\title{
Abnormal Inflammatory Status Promotes Lymphatic Metastasis of Gallbladder Cancer Cells Through the CACUL1/NRF2/ITGBL1/ITGA9/VEGF-C Pathway
}

Ying Kong ( $\nabla$ yingkong76@xjtu.edu.cn )

Xi'an Jiaotong University Medical College First Affiliated Hospital Department of Medical Oncology

Kai Wang

Xi'an Jiaotong University Medical College First Affiliated Hospital

Ai-li Suo

Xi'an Jiaotong University Second Affiliated Hospital

\section{Research}

Keywords: CACUL1, ITGBL1, Gallbladder cancer, Metastasis, Lymphangiogenesis

Posted Date: October 5th, 2021

DOl: https://doi.org/10.21203/rs.3.rs-944649/v1

License: (9) (i) This work is licensed under a Creative Commons Attribution 4.0 International License. Read

Full License 


\section{Abstract}

Background: Gallbladder cancer (GBC) is a highly fatal disease with poor prognosis, but the aetiology is poorly understood. Long standing gallstone and chronic inflammation had been observed to be risk factors for GBC. Gallstone and chronic infection may lead to increased turnover of primary bile acids to secondary bile acids and inflammatory cytokines, which were known tumor promoters and might be responsible for GBC. But the exact molecular mechanism was not fully understood.

Results: Our results showed that gallstones and chronic infection could increase the levels of inflammatory cytokines, and promoted the expression of CACUL1 and ITGBL1. Our study furtherly identified the highly expressed patients of CACUL1 and ITGBL1 had a poor prognosis, and them therefore might serve as a potential prognostic biomarker for GBC patients. CACUL1 promoted the expression of ITGBL1 through NRF2. Furthermore, ITGBL1 promoted the migration and invasion of GBC cells. In addition, ITGBL1 was found to induce lymphangiogenesis through the ITGA9/VEGF-C pathway and promote lymphatic metastasis.

Conclusions: Our study provided new insight into GBC pathogenesis that chronic bacterial infection and gallstones leading to the production of carcinogenic precursors and inflammatory cytokines promote lymphangiogenesis and lymph node metastasis of cancer cells through CACUL1/NRF2/ITGBL1/ ITGA9/VEGFC pathway.

\section{Background}

GBC is the fifth commonest cancer of the gastrointestinal tract. GBC is an aggressive disease with a dismal prognosis and has marked ethnic and geographical variations in incidence. GBC is a more common tumor in females than males. Only $15 \%-47 \%$ of the preoperatively known GBC are suitable for resection. The prognosis of GBC is poor, and the 5 -year overall survival rate is less than $5 \%$. More than $50 \%$ of all patients with GBC exhibit lymph node metastases (LNM)[1, 2].

Therefore, disclosuring the mechanism of GBC lymphatic metastasis can help improve the treatment and prognosis of patients. However, the definite mechanisms of underlying lymphatic metastasis in GBC are largely unknown.

Some studies showed that there were gallstones present in nearly $88 \%$ of GBC cases. The important role of gallstone in the development of GBC had been established in several previous studies. Especially, large, cholesterol or combined gallstones $(>1.5 \mathrm{~cm})$ were found in $68.2 \%$ of the tumors. In addition, small cholesterol, pigmented or mixed gallstones, and bile sludge were existed in $31.8 \%$ of the tumors [3-5].

Chronic inflammation was also strongly associated with the malignant transformation of cells. Chronic inflammation causes DNA damage, the release of cytokines and growth factors and thus, predisposes cells to oncogenic transformation. Chronic bacterial infection of GBC was also a risk factor for biliary malignancy. Some studies have reported an association between infections and GBC risk, clinical and epidemiological studies have also suggested a link to bacterial infection, such as by Helicobacter species[4, 6-9]. Some studies clearly demonstrate that Helicobacter can resist bile salts and can survive and colonize in the gallbladder. H. pylori, $\mathrm{H}$. hepaticus and $\mathrm{H}$. bilis had been isolated from humans with gallbladder disease such 
as cholecystitis, gallstone, GBC and bile tract cancer[7, 10,11]. Studies have shown that urease can induce calcium precipitation by Helicobacter pylori, thereby triggering the formation of gallstones [12]. A study clearly demonstrated the presence of a mixed bacterial group in gallstones. There are several species of bacteria that are believed to be associated with GBC. H. pylori and H. bilis cause a 2.7- to 12-fold increase in the incidence of GBC $[7,13]$. Helicobacter infection is an important risk factor for GBC. These changes may affect malignant transformation by changing tumor suppressor genes or proto-oncogenes.

Bacterial degradation of bile and inflammation cytokines may also play some roles in the carcinogenic process. Cytokines secreted by inflammatory cells, such as TNF-a, IL-1, and IL-6, play important roles in cancerrelated inflammation[14, 15]. Hydrophobic acids such as deoxycholic acid (DCA) are known to be associated with carcinogenesis. In animal models, DCA and lithocholic acid (LCA) have been implicated in the development of bile duct cancer. Elevated concentrations of DCA and LCA have also been reported in patients with choledochal cysts and abnormal connections of the pancreaticobiliary duct. Although studies have shown that secondary bile acids can be carcinogenic, there are few reports evaluating bile acid composition in GBC, likely due to the rarity of this disease[16-19]. The chronic bacterial infection leads to the production of carcinogen precursors, which may be one of the causes of the onset of GBC, thus becoming a target for the prevention of GBC. The study suggested that bacterial degradation of primary bile acids in the gallbladder may be responsible for GBC. But the exact molecular mechanism was not fully understood.

Our previous studies found that Helicobacter and deoxycholic acid could promote the expression of CACUL1 and promote the proliferation and metastasis of tumor cells[20-22]. Our study also found that CACUL1 was highly expressed in GBC. It suggests that it may be related to the incidence of GBC. But the exact function is unknown. High expression of CACUL1 is correlated with tumor metastasis, and patients with CACUL1 high expression have a poor prognosis. In addition, GSE105055 analysis in the GEO database was revealed that ITGBL1 was one differentially regulated gene of CACUL1 downstream, and CACUL1 was positively correlated with the expression of ITGBL1. Further experimental results showed that CACUL1 could promote the expression of ITGBL1 through NRF2. Some studies showed that ITGBL1 was closely related to metastasis[2325]. At present, there is little evidence revealing the role of ITGBL1 in GBC, the further research needs to be conducted to explore more specific mechanisms.

We investigated the expression pattern and prognostic value of ITGBL1 in GBC. We found that compared with non-tumor tissues, the expression of ITGBL1 in GBC tissues was significantly up-regulated, and ITGBL1 expression was associated with distant metastasis and poor prognosis in GBC patients. The transfection of ITGBL1 could promote the proliferation and metastasis of tumor cells. STRING datasets(https://string$\mathrm{db}$.org/cgi/input.pl) revealed that ITGBL1 was related to the ITGA9(integrin a9)/VEGF-C signaling pathway. Our results showed that ITGBL1 could promote the expression of ITGA9. ITGA9 protein binds to integrin $\beta 1$ and thus forms a receptor that interacts with its corresponding ligands present in the extracellular matrix, including tenascin-C, osteopontin, and vascular endothelial growth factor-C[26-29]. It is important that some researches found that ITGA9 could regulate VEGF expression to promote angiogenesis and lymphangiogenesis via FAK/Src signaling and its downstream targets, including p38 MAPK, p-ERK, and p-GSK3 $\beta / \beta$-catenin signaling[29-31]. This provide a potential explanation for the molecular mechanisms underlying ITGBL1's role in lymphatic development, which could promote lympho-angiogenesis and metastasis. In vitro experiments 
showed that the expression of VEGF-C was increased in the supernatant of GBC cells transfected with ITGBL1. In vivo experiments showed that ITGBL1 could promote lymphangiogenesis and metastasis of cancer cells.

In conclusion, our results showed that the chronic infection and the gallbladder gallstones could increase the levels of inflammatory cytokines, and promoted the expression of CACUL1. CACUL1 promoted the expression of ITGBL1 through NRF2. Our study furtherly identified that the highly expressed patients of CACUL1 and ITGBL1 had a poor prognosis, and they might serve as a potential prognostic biomarker for GBC patients. Furthermore, ITGBL1 promoted the migration and invasion of GBC cells. ITGBL1 has been found to induce lymphangiogenesis through the ITGA9/VEGF-C pathway and promote GBC lymphatic metastasis. Our study provided new insight into GBC pathogenesis and opportunities for further exploration in future studies.

\section{Results}

\section{Detection of Helicobacter species (H. pylori, H. bilis and H. hepaticus) and other bacteria by PCR}

Each species of Helicobacter was analyzed. Helicobacter species were detected in the bile samples of GBC patients $(28 / 80,35 \%)$ significantly more often than that in the normal gallbladders group $(1 / 20,5 \%)(p<0.05)$. Helicobacter species were detected in the bile samples of gallstone patients $(16 / 60,26.7 \%)$, but there was no significant difference between GBC and the gallstone patients $(p>0.05)$.

The total number of H.pylori found in the GBC patients (21/80, 26.3\%), in patients with gallstone $(11 / 60,18.3$ $\%)$, and the normal gallbladders group $(1 / 20,5 \%)$, but there was no significant differences among groups ( $p>$ $0.05)$. While the respective total number of H.bilis found in GBC patients, gallstone and control group was (9/80, $11.3 \%),(6 / 60,10 \%)$ and $(0 / 20,0 \%)$. Similarly, no PCR product from $\mathrm{H}$. hepaticus was found in either the benign or the malignant group. A mixed infection of H.pylori and H.bilis was detected in $(2 / 80,2.5 \%) \mathrm{GBC}$ and $(1 / 60,1.7 \%)$ gallstone patients, respectively (Table 1$)$. 
Table 1

Helicobacter species and other bacteria detected in bile samples of GBC

\begin{tabular}{|c|c|c|c|c|c|c|}
\hline \multirow[t]{2}{*}{ Diseases } & \multicolumn{5}{|c|}{ Number of Helicobacter positive (\%) } & \multirow{2}{*}{$\begin{array}{l}\begin{array}{l}\text { Number } \\
\text { of other } \\
\text { bacteria } \\
\text { (\%) }\end{array} \\
\begin{array}{l}\text { No. of } \\
\text { other } \\
\text { bacterial } \\
\text { positive }\end{array}\end{array}$} \\
\hline & H. pylori & $\begin{array}{l}\mathrm{H} \text {. } \\
\text { bilis }\end{array}$ & $\begin{array}{l}\mathrm{H} \text {. } \\
\text { pylori and } \mathrm{H} \text {. } \\
\text { bilis }\end{array}$ & $\begin{array}{l}\text { Total No. } \\
\text { of Helicobacter spp. }\end{array}$ & $\begin{array}{l}\text { Helicobacter species. } \\
\text { and other bacteria }\end{array}$ & \\
\hline $\begin{array}{l}\mathrm{GBC}(\mathrm{n}= \\
80)\end{array}$ & $21(26.3)$ & $\begin{array}{l}9 \\
(11.3)\end{array}$ & $2(2.5)$ & $28(35)$ & $3(3.75)$ & $5(6.25)$ \\
\hline $\begin{array}{l}\text { Gallstone } \\
(n=60)\end{array}$ & $\begin{array}{l}11 \\
(18.3)\end{array}$ & $6(10)$ & $1(1.7)$ & $16(26.7)$ & $2(3.3)$ & $3(5)$ \\
\hline $\begin{array}{l}\text { Control } \\
(n=20)\end{array}$ & $1(5)$ & $0(0)$ & $0(0)$ & $1(5)$ & $0(0)$ & $0(0)$ \\
\hline
\end{tabular}

The infection of other bacteria was detected in (5/80, $6.25 \%) \mathrm{GBC}$ and $(3 / 60,5 \%)$ gallstone patients, none was found in the control group. The mixed infection of Helicobacter species and other bacteria were detected in $(3 / 80,3.75 \%) \mathrm{GBC}$ and $(2 / 60,3.3 \%)$ gallstone patients, respectively.

\section{Markers of inflammation analysis among GBC, gallstone, and normal groups}

Cytokines are the key mediators that mediate the host's inflammatory response. Therefore, we measured the

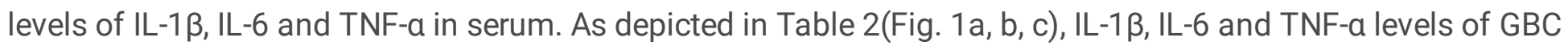
groups and gallstone groups were observably increased compared to the normal groups $(P<0.05)$. IL-1 $\beta$, IL- 6 and TNF-a levels was no significant difference between GBC groups and gallstone groups. Among GBC patients with different condition, the levels of IL-1 $\beta$, IL- 6 and TNF-a were no significant different (Supplementary Table 2) (Fig. 1d, e, f). However, the results showed that in GBC patients with gallstone and/or bacterial infection groups, Cytokines levels had an increasing trend compared to GBC with gallstone and/or bacterial infection negative groups. The results demonstrated that gallstone and bacterial infection promoted the synthesis of cytokines. 
Table 2

Markers of inflammation analysis among GBC, gallstone, and normal groups

\begin{tabular}{|c|c|c|c|}
\hline & Groups(mean \pm & $\mathrm{mL})$ & \\
\hline & Cancer(n= 80) & Gallstone $(n=60)$ & Normal( $n=20)$ \\
\hline $\mathrm{IL}-1 \beta(\mathrm{pg} / \mathrm{mL})$ & $3.96 \pm 2.76$ & $3.24 \pm 2.35$ & $1.82 \pm 0.87$ \\
\hline TNF-a $(\mathrm{pg} / \mathrm{mL})$ & $14.12 \pm 7.35$ & $13.17 \pm 4.91$ & $9.64 \pm 4.26$ \\
\hline IL-6 (pg/mL) & $11.06 \pm 6.16$ & $10.10 \pm 6.26$ & $6.73 \pm 4.55$ \\
\hline
\end{tabular}

\section{The expression of CACUL1 and ITGBL1 is up-regulated in GBC tissues}

To illustrate the expression pattern of CACUL1 and ITGBL1, we first detected the mRNA expression level of CACUL1 and ITGBL1 in GBC tissues, gallstone, and normal tissues. The results showed that CACUL1 and ITGBL1 expression was significantly increased in GBC tissues comparing with gallstone and normal tissues (Fig. 2a, b).

GBC patients were subdivided into patients with gallstone, patients with bacterial infection, patients with gallstone and bacterial infection, patients without gallstone and bacterial infection. CACUL1 and ITGBL1 expression were analyzed in these different GBC patients. Previously published papers suggested that oxidative stress, H.pylori, and DCA could increase the expression of CACUL1. CACUL1 and ITGBL1 expression were the high in GBC patients with gallstone or bacterial infection. But there was no significant difference among GBC groups with different conditions (Fig. 2c, d). Furthermore, we validated the protein expression of ITGBL1 in another 7 pairs of resected representative specimens (tumor tissues and paired adjacent non-tumor tissues) from GBC patients using western blotting analysis. Consistently, an increase of ITGBL1 expression was observed in GBC tissues compared with the paired adjacent non-tumor tissues (Fig. 2e, *, P<0.05, **, P< 0.01.).

To further address the protein change of CACUL1 and ITGBL1 in GBC tissues, IHC analyses were performed in GBC, cholecystitis, and normal tissues. The representative staining of CACUL1 and ITGBL1 expression in GBC, as well as non-tumor tissues, were shown in Fig. 3a,b. The positive immunostaining for CACUL1 was predominantly observed in the cytoplasm and extracellular matrix (ECM), and positive immunostaining for ITGBL1 was also predominantly observed in the cytoplasm, ECM, nerve tract, and capillary of GBC (Fig. 3c). We found that CACUL1 and ITGBL1 were significantly up-regulated in GBC tissues compared with non-tumor tissues (Fig. 3a,b, $\mathrm{P}<0.05$ ).

\section{The expression level of ITGBL1 related to microvascular and lymphatic microvessels density in GBC tissues}

In the tissues expressing high levels of ITGBL1 (++or+++) and the tissues with low expression levels of ITGBL1 (- or + ), we counted these microvascular and determined the mean \pm SD of microvascular density to be $16.53 \pm 3.24$ in the ITGBL1 high-expression patients, $11.67 \pm 1.23$ in the ITGBL1 low-expression patients. Microvascular density in the ITGBL1 high-expression patients was significantly higher than that in the ITGBL1 
low-expression patients (Fig. 3d, $\mathrm{p}<0.05$ ). A positive correlation was detected between the expression of ITGBL1 and microvascular density.

To compare lymphatic microvessel density in these tissues, we determined the mean \pm SD of lymphatic microvessel density to be $7.55 \pm 1.29$ in the ITGBL1 high-expression patients, $3.24 \pm 0.86$ in the ITGBL1 lowexpression patients. Lymphatic microvessel density in the ITGBL1 high-expression patients was significantly higher than that in the ITGBL1 low-expression patients (Fig. 3d, p < 0.01). Our study found that microvascular and lymphatic microvessel density did significantly correlate with the expression of ITGBL1(Table 3).

Table 3

Microvascular and lymphatic microvessel density

\begin{tabular}{|lcllll|}
\hline $\begin{array}{l}\text { ITGBL1 } \\
\text { expression }\end{array}$ & Number & $\begin{array}{l}\text { Microvascular } \\
\text { density }\end{array}$ & p value & $\begin{array}{l}\text { Lymphatic microvessel } \\
\text { density }\end{array}$ & p value \\
\hline$(-$ or +$)$ & 25 & $11.67 \pm 1.23$ & $t=2.34$ & $3.24 \pm 0.86$ & $t=3.57$ \\
\hline$(++$ or +++$)$ & 55 & $16.53 \pm 3.24$ & $<0.05^{*}$ & $7.55 \pm 1.29$ & $0.01^{* *}$ \\
\hline & & & & \\
\hline
\end{tabular}

Correlation of CACUL1 and ITGBL1 expression with clinicopathological parameters in patients with GBC

To determine the clinical significance of CACUL1 and ITGBL1 expression in GBC, we used the Chi-square test to assess the correlation between CACUL1 and ITGBL1 expression and corresponding patients' clinicopathologic parameters shown in Table 4. The results showed that CACUL1 and ITGBL1 expression in GBC tissues was significantly correlated with $\mathrm{N}$ classification, TNM stage, lymphatic metastasis, $(P<0.05)$. While there was no significant correlation with age, gender, pathological type, Tumor location, Tumor differentiation. 
Table 4

Correlation between CACUL1 and ITGBL1 expression and clinicopathologic parameters in GBC patients

\begin{tabular}{|c|c|c|c|c|c|c|}
\hline \multirow{2}{*}{$\begin{array}{l}\text { Clinicopathological } \\
\text { parameter }\end{array}$} & \multirow{2}{*}{$\begin{array}{l}\text { Total } \\
80\end{array}$} & \multicolumn{2}{|c|}{ Expression of CACUL1 } & \multirow[t]{2}{*}{$p$ value } & \multicolumn{2}{|c|}{ Expression of ITGBL1 } \\
\hline & & $\begin{array}{l}\text { Low(- } \\
\text { ort })(n= \\
22,27.5 \%)\end{array}$ & $\begin{array}{l}\text { High(++ } \\
\text { or+++)(n= } \\
58,72.5 \%)\end{array}$ & & $\begin{array}{l}\text { Low(- ort) } \\
(n= \\
25,31.25 \%)\end{array}$ & $\begin{array}{l}\text { High }(++ \\
\text { ort+++(n }= \\
55,68.75 \%)\end{array}$ \\
\hline
\end{tabular}

Age (years)

$\begin{array}{llllllll}<60 & 27 & 10 & 17 & >0.05 & 9 & 18 & >0.05 \\ \geq 60 & 53 & 12 & 41 & & 16 & 37 & \end{array}$

\section{Gender}

$\begin{array}{llllllll}\text { Male } & 12 & 2 & 10 & >0.05 & 3 & 9 & >0.05 \\ \text { Female } & 68 & 20 & 48 & & 22 & 46 & \end{array}$

\section{Tumor location}

$\begin{array}{llllllll}\text { Gallbladder neck } & 33 & 9 & 24 & >0.05 & 10 & 23 & >0.05 \\ \begin{array}{l}\text { Gallbladder bottom } \\ \text { and body }\end{array} & 47 & 13 & 34 & & 15 & 32 & \end{array}$

\section{Pathological type}

$\begin{array}{llllllll}\text { other type } & 18 & 6 & 12 & >0.05 & 4 & 14 & >0.05 \\ \text { Adenocarcinoma } & 62 & 16 & 46 & & 21 & 41 & \end{array}$

\section{Tumor} differentiation

\begin{tabular}{llllllll}
$\begin{array}{l}\text { Highly and } \\
\text { moderately } \\
\text { differentiated }\end{array}$ & 37 & 12 & 25 & $>0.05$ & 8 & 29 & $>0.05$ \\
\hline Pooly and & & & & & & &
\end{tabular}

$\begin{array}{llllll}\begin{array}{l}\text { Poorly and } \\ \text { undifferentiated }\end{array} & 43 & 10 & 33 & 17 & 26\end{array}$

\section{$\mathrm{N}$ classification}

$\begin{array}{llllrrrr}\text { N0 } & 23 & 10 & 13 & <0.05^{*} & 11 & 12 & <0.05^{*} \\ \text { N1, } 2 & 57 & 12 & 45 & 14 & 43 & \end{array}$

\section{TNM stage}

$\begin{array}{llllllll}I+I I & 15 & 8 & 7 & <0.05^{*} & 9 & 6 & <0.05^{*} \\ \text { III+ IV } & 65 & 14 & 51 & 16 & 49\end{array}$

\footnotetext{
${ }^{\star} p<0.05,{ }^{* \star} p<0.01$ was considered statistically significant

$P$ value was calculated by $\chi^{2}$ test.
} 


\begin{tabular}{|c|c|c|c|c|c|c|c|}
\hline \multirow{2}{*}{$\begin{array}{l}\text { Clinicopathological } \\
\text { parameter }\end{array}$} & \multirow{2}{*}{$\begin{array}{l}\text { Total } \\
80\end{array}$} & \multicolumn{2}{|c|}{ Expression of CACUL1 } & \multirow[t]{2}{*}{$\mathrm{p}$ value } & \multicolumn{2}{|c|}{ Expression of ITGBL1 } & \multirow[t]{2}{*}{$\mathrm{p}$ value } \\
\hline & & $\begin{array}{l}\text { Low(- } \\
\text { ort) }(n= \\
22,27.5 \%)\end{array}$ & $\begin{array}{l}\text { High(++ } \\
\text { Or+++(n) }(\mathrm{n}= \\
58,72.5 \%)\end{array}$ & & $\begin{array}{l}\text { Low }(- \text { or }+) \\
(n= \\
25,31.25 \%)\end{array}$ & $\begin{array}{l}\operatorname{High}(++ \\
\text { ort+++(n= } \\
55,68.75 \%)\end{array}$ & \\
\hline \multicolumn{8}{|l|}{$\begin{array}{l}\text { lymphatic } \\
\text { metastasis }\end{array}$} \\
\hline Absent & 32 & 14 & 18 & ¿.01** & 15 & 17 & $<0.05^{\star}$ \\
\hline Present & 48 & 8 & 40 & & 10 & 38 & \\
\hline \multicolumn{8}{|c|}{${ }^{\star} p<0.05,{ }^{*} \mathrm{p}<0.01$ was considered statistically significant } \\
\hline$P$ value was calcula & d by $\chi^{2}$ & & & & & & \\
\hline
\end{tabular}

\section{High CACUL1 and ITGBL1 expression is predictive of poor survival in GBC patients}

80 patients were enrolled in the survival analysis. 69 patients died, while the remaining 11 patients were alive at the last follow-up $($ Oct 31, 2017). Kaplan-Meier analysis and the log-rank test were employed to calculate the effect of CACUL1 and ITGBL1 expression on patient's overall survival. Results revealed that the high CACUL1 and ITGBL1 group had significantly poorer overall survival than the low $\operatorname{CACUL} 1(\chi 2=5.497, p=0.019)$ and ITGBL1 $(X 2=10.916, p<0.01)$ group (Fig. 4a).

\section{CACUL1 upregulated the expression of ITGBL1 through NRF2}

We found that CACUL1 upregulated the expression of ITGBL1 (Fig. 4b). The bioinformatics analysis that Nrf2 directly binds to the promoter of the ITGBL1 and influences its transcriptional regulation. Through a sequence search of the ITGBL1 promoter by JASPAR (http://jaspar.genereg.net/), we found NRF2 elements in the promoter region of ITGBL1(chromosome:GRCh38:13:101450593:101721456:1): -1637 to $-1627 ;-1701$ to -1691 (Fig. 4c). The published literature showed that CACUL1 was a regulator of Nrf2 ubiquitination. The activity of Nrf2 was tightly regulated at basal levels through its ubiquitination by Cul3-Keap1 and consequential degradation. Upon exposure to stress, the Cul3-Keap1 ligase is inhibited by CACUL1, leading to Nrf2 stabilization and activation[21]. Therefore, we speculated that CACUL1 promotes ITGBL1 expression through NRF2.

NRF2 is the predominant transcription activator responsible for coordinated up-regulation of ARE-driven antioxidant and detoxification genes. And NRF2 was a key transcription factor during tumor cell development. The bioinformatics analysis that ITGBL1 was the positive relationship and co-expressed with CACUL1 and NRF2(NFE2L2) in GEPIA (Gene Expression Profiling Interactive Analysis, http://gepia.cancer-

pku.cn/index.html) database (Fig. 4d) and ENCORI (The Encyclopedia of RNA Interactomes) database[32], we investigated whether ITGBL1 was regulated by NRF2. We performed a ChIP assay to enrich the NRF2-bound DNA fragments and found that NRF2 strongly bound the ITGBL1 promoter region containing the - 1637 to -1627 site, but was very weakly combined with the -1701 to -1691 site (Fig. 4e).

We further investigated the regulatory activity of NRF2 on the ITGBL1 promoter using dual-luciferase reporter assays and found that ITGBL1 promoter activity decreased in the cells transfected with pGL3-ITGBL1 
-1637/-1627 with a mutated NRF2-binding motif compared with the control cells transfected with pGL3ITGBL1-1637/-1627 with the wild-type NRF2-binding motif (Fig. 4f). Moreover, we also performed dualluciferase reporter assays to compare with the ITGBL1 promoter activity upon the transient transfection of pGL3-ITGBL1 -1637/-1627 in a stable subclone of cell with that in shRNA-mediated NRF2, NRF2-

overexpressing cells, and their control cells. NRF2 overexpression enhanced the activity of ITGBL1 promoters compared with their respective control cells (Fig. 4g).

To further confirm the regulatory effect of NRF2 on ITGBL1 transcription levels, the mRNA expression levels of ITGBL1 in shRNA-mediated NRF2 cells, NRF2-overexpressing cells, and their corresponding control cells were measured by RT-qPCR. The ITGBL1 mRNA expression level was downregulated in shRNA-mediated NRF2 cells and upregulated in NRF2-overexpressing cells compared with their respective control cells (Fig. 4h). These results confirm that ITGBL1 is a positively regulated transcriptional target of NRF2. Together, these results demonstrate that NRF2 regulates the activity of the ITGBL1 promoter. CACUL1 promotes NRF2 binding to the promoter region of ITGBL1, whereas silencing NRF2 attenuated the upregulation of ITGBL1 induced by CACUL1(Fig. 4i).

\section{ITGBL1 promotes cell migration and invasion in vitro}

We also performed a wound-healing assay to qualitatively observe the ITGBL1 induced motility in GBC-SD cells. A scratch was made in $90 \%$ confluent ITGBL1 and NC-transfected cells. Cells were allowed to move into the scratch wound for $24 \mathrm{~h}$, and we observed that more cells transfected with ITGBL1 had moved into the scratch wound than NC transfected cells (Fig. 5a). The results of the scratch test were analyzed by ImageJ software, and the scratch area and wound healing percentage were calculated. The wound healing percentage of the NC-transfected cells at $24 \mathrm{~h}$ was $28.3 \%$. The wound healing percentage of ITGBL1-transfected cells at 24h was: $51.7 \%$. The results showed that ITGBL1 could significantly promote the migration of tumor cells.

Transwell assays were carried out to explore the effect of ITGBL1 on the invasion capability of GBC cells. The results indicated that the overexpression of ITGBL1 promoted the invasion of cells, and the inhibition of ITGBL1 expression decreased the invasion potential of cells (Fig. 5b). Together, these data suggested that ITGBL1 promoted the migration and invasion of GBC cells in vitro and that ITGBL1 functions as an oncogene in GBC.

\section{Correlation between the expression of ITGBL1 and the ITGA9/VEGF-C signaling pathway}

Our results showed that ITGBL1 may participate in GBC invasion and promoted tumor cell metastasis. Moreover, the bioinformatics analysis showed a strong correlation between ITGBL1 expression and the ITGA9/VEGF-C signaling pathway (Fig. 6a) in the STRING database[33]. The bioinformatics analysis that ITGBL1 was a positive relationship and co-expressed with VEGF-C in various tumors such as colon cancer (Fig. 6b) in ENCORI database[32]. ITGBL1 expression was positively associated with the expression of ITGA9, and positively with the expression of VEGF-C, as the expression of lymph angiogenesis markers.

Increasing ITGBL1 expression could promote the expression of ITGA9 and VEGF-C (Fig. 6c, d). In addition, the furtherly result showed that the concentration of VEGF-C in the supernatant of cells transfected with ITGBL1 
was increased (Fig. 6e). Taken together, these data suggested that ITGBL1 might activate ITGA9/VEGF-C signal pathway to induce lymphangiogenesis and promote tumor cells metastasis.

\section{ITGBL1 promotes tumor growth, angiogenesis, lymphangiogenesis and metastasis in nude mice}

To confirm the in vitro phenotype of ITGBL1, we examined the effect of ITGBL1 on SGC-996 cell growth in nude mice. Consistent with the in vitro results, the tumor volume and weight were significantly greater in the ITGBL1 overexpression group than in the NC group (Fig. 7a, b, c). On the other hand, the tumor volume and weight were lower in the ITGBL1 inhibitor group than that in the NC group (Fig. 7a,b,c).

Next, we used the GBC cell line, SGC-996, which showed lung metastasis, to measure the effect of ITGBL1 on metastasis. These serial sections of the lungs stained with hematoxylin-eosin were used to identify metastatic lesions (Fig. 7d). The incidence of lung metastasis in the ITGBL1 group was 5\% (1/20), but the incidence of lung metastasis in the ITGBL1 inhibitor group and the NC group was zero $(0 / 20)$. These findings strongly suggest the role of ITGBL1 as a promoter of tumor dissemination.

In the tumor nodules tissues of the ITGBL1 overexpression group and the NC group and the ITGBL1 inhibitor group, we counted these microvascular and lymphatic microvessels, and determined the mean \pm SD of microvascular density to be $22.35 \pm 8.56$ in the tumor nodules tissues of the ITGBL 1 overexpression group, $10.32 \pm 5.67$ in the NC group, and $7.89 \pm 3.55$ in the ITGBL1 inhibitor group. Microvascular density in the tumor nodules tissues of the ITGBL1 overexpression group was significantly higher than that in the NC group and the ITGBL1 inhibitor group $(p<0.05)$ (Table 5). A positive correlation was detected between the expression of ITGBL1 and microvascular density.

Table 5

The density of tumor blood vessels and lymph vessel in the tumor nodules of the ITGBL1 overexpression groups, the NC groups and the ITGBL1 inhibitor groups.

\begin{tabular}{|c|c|c|c|}
\hline & $\mathbf{N}$ & Microvascular density & Lymphatic microvessel density \\
\hline NC group & 10 & $10.32 \pm 5.67$ & $2.33 \pm 0.76$ \\
\hline ITGBL1 inhibitor group & 10 & $7.89 \pm 3.55$ & $1.21 \pm 0.35$ \\
\hline ITGBL1 overexpression group & 20 & $22.35 \pm 8.56$ & $4.84 \pm 1.64$ \\
\hline \multicolumn{4}{|c|}{$\begin{array}{l}\text { In microvascular density, statistical significance between NC group and ITGBL1 inhibitor group }(t=0.65, P \\
>0.05) \text {. Statistical significance between ITGBL1 overexpression group and NC group }(t=2.33, P<0.05) \text {. } \\
\text { Statistical significance between ITGBL1 overexpression group and ITGBL1 inhibitor group }(t=3.19, P< \\
0.01) \text {. }\end{array}$} \\
\hline \multicolumn{4}{|c|}{$\begin{array}{l}\text { In lymphatic microvessel density, statistical significance between NC group and ITGBL } 1 \text { inhibitor group }(t= \\
0.87, P>0.05) \text {. Statistical significance between ITGBL1 overexpression group and NC group }(t=1.62, P< \\
0.05) \text {. Statistical significance between ITGBL } 1 \text { overexpression group and ITGBL1 inhibitor group }(t=2.72 \text {, } \\
P<0.05) \text {. }\end{array}$} \\
\hline
\end{tabular}

To compare lymphatic microvessel density in these tissues, we determined the mean \pm SD of lymphatic microvessel density to be $4.84 \pm 1.64$ in the tumor nodules tissues of the ITGBL 1 overexpression group, $2.33 \pm$ 0.76 in the NC group, and $1.21 \pm 0.35$ in the ITGBL1 inhibitor group. Our experimental study found that lymphatic microvessel density did significantly correlate with the expression of ITGBL1 $(p<0.05)($ Table 5). 
In addition, the density of tumor blood vessels and lymph vessels found in the tumor nodules of the ITGBL1 overexpression group was much higher than those in the NC group and the ITGBL1 inhibitor group (Fig. 7e).

\section{Discussion}

GBC is a rare malignant tumor of the gastrointestinal tract, but it is the most common cancer of the biliary tract. It differs from other cancers of the digestive tract, as being several-fold more common in women than in men[34, 35]. The signs and symptoms of GBC are nonspecific and usually occur late in the clinical course of the disease. GBC is a very aggressive type of cancer, with a median survival period of 3-11 months and a 5year survival period of 3-13\%.More than half of all GBCs are not resectable at the time of diagnosis[4, 34, 36]. Therefore, the diagnosis is usually made when cancer has entered an advanced stage, and the prognosis for survival in $90 \%$ of cases is less than 5 years.

Several etiological factors have been implicated in the causation of GBC, in addition to age-, race-, and genderrelated differences, there are also geographic factors determining the incidence of GBC, several risk factors have been proposed[4, 15, 34, 37]. Although its exact etiology is unknown, the gallstones and pathogenic infection by bacteria are the most important risk factors of these etiological factors $[4,34,38]$. The gallstonerelated gallbladder carcinogenesis occurs mainly through the metaplasia-dysplasia-carcinoma pathway rather than through the transformation of a pre-existing benign tumor lesion. Metaplasia is also found in $66 \%$ of gallbladders with infiltrating carcinoma[39].Gallstones were detected in $75 \%$ of surgical cases and $90 \%$ of autopsy cases with $\mathrm{GBC}[38,40]$. In addition, the severity of gallbladder epithelial lesions worsens with the increase in weight, volume, and size of gallstones[41]. Our results indicated that more than $48.75 \%$ (39/80) of patients with GBC had gallstones. Therefore gallstone was one of the important factors for GBC.

The variant analysis had shown that pathogenic infection by bacteria forms an important independent risk factor for gallstones and GBC. Chronic infection of the gallbladder may contribute to the onset of GBC, via gallstone formation[4, 34]. Most available evidence implicates S. typhi and S. paratyphi and Helicobacter species. However, further researches are needed to confirm the relationship between these bacterial infections and GBC development. Because of the toxicity of deoxycholic acid and lithocholic acid, consisting of major ingredients of bile, most bacteria barely survive and proliferate in bile. But some Helicobacter species, however, show bile tolerance, and colonization of bile acid-tolerant Helicobacter species in the liver of experimental animals was reported, among which helicobacter infection was the main pathogenic bacteria. Especially, $\mathrm{H}$. hepaticus and $\mathrm{H}$. bilis were isolated and cultivated from bile and liver tissue of mice, which has been noted as a causative factor of chronic active hepatitis and hepatic neoplasm[7, 10,11]. H.hepaticus is a known pathogen that can cause chronic active bile duct infection to progress to liver cancer[42]. Whether Helicobacter is the number one cause of the type of gallstone formation that ultimately leads to malignancy or is itself a risk factor for the pathogenesis of $\mathrm{GBC}$, is yet to be determined.

Although several researches have surveyed the roles of bacterial infection in GBC risk, the discrepant results have been reported. There are several possible explanations for the apparent difference in the results of the relationship between GBC risk and bacterial infection. Using different samples and methods may lead to differences among results. There are many methods to detect bacterial infections, such as serological 
examination, culture method, and PCR, among which PCR is the most sensitive method for detecting bacteria in bile samples $[7,11]$.

For example, Helicobacter DNA has been detected in human bile, hepatobiliary tissue, and primary biliary cirrhosis by PCR assays in different parts of the world. PCR-based detection rates of different species of Helicobacter species in GBC vary from 0\%-82.8\% [43]. The reasons for the different detection rates were unclear, but it is possible that the chance of bacterial infection may have decreased in recent years as a result of antibiotic administration. Using species-specific primers, H.bilis was found in 35 out of 67 specimens (52.2\%) from four different studies, whereas $\mathrm{H}$. hepaticus was searched for in two studies, but only in one study were four out of 19 specimens $(21.1 \%)$ found to be positive for the bacterium[7, 11, 44]. Murata et al [45]showed that H.bilis specific sequences could be amplified in 3 of 11 (27.2\%) GBC cases. One study conducted in Japanese and Thai populations showed that patients positive for H.bilis had a 6-fold higher risk of GBC[46, 47]. H.bilis and H.pylori have been identified in bile specimens and associated with the risk of GBC. Recently, Matsukura et al[47]reported the existence of H.bilis in bile juice in Japanese patients with bile duct cancer and cholecystolithiasis. They employed the PCR method in the same way and observed positive amplification in $87 \%$ of patients with bile duct or GBC, but in only $50 \%$ of patients with cholecystitis, gallstones or both, and $29 \%$ of those with non-biliary diseases. However, it is premature to conclude the role of Helicobacter species in causing GBC. We clarified the nature of the microbial communities present in bile in patients with GBC using 16S rRNA metagenomics.

Our results showed that $48.75 \%$ (39/80) of the 80 patients with GBC were complicated with gallstone, among which the bacterial infection rate in GBC with gallstone was $41.03 \%(16 / 39)$, and the bacterial infection rate was $37.5 \%(30 / 80)$ in the patients with GBC, among which the Helicobacter infection rate was $35 \%(28 / 80)$, and $6.25 \%(5 / 80)$ infections were caused by other bacteria(Contains the double infection of Helicobacter species and other bacteria). However, in 60 patients with gallbladder stones, the bacterial infection rate was $28.33 \%$ (17/60), but the difference between GBC and gallstone patients was not statistically significant. However, 5\% $(1 / 20)$ bacteria were detected in the 20 normal gallbladder tissues, and the difference was statistically significant from those of patients with GBC. The above results suggested that bacterial infection is one of the pathogenesis factors of gallbladder stones and GBC, and bacterial infection and gallstones promote each other, causing the occurrence of GBC.

There are several pathways by which Helicobacter is capable of inducing cancer. One mechanism involves the enhanced production of free radicals and inflammation causing an increased rate of host cell mutation. It has been proposed that Helicobacter induces inflammation and locally high levels of TNF-a, IL- 6 and IL-1 $\beta[15,34$, 36]. Our results showed that the content of inflammatory cytokines in GBC was significantly higher than that in control non-tumor tissues, especially in patients with GBC complicated with bacterial infection or gallstones, the content of inflammatory cytokines is higher.

The bacterial infection is one of the factors that cause the decomposition of bile acid salt to produce secondary bile acid salt and oxidative stress and is also one of the factors that cause the malignant transformation of GBC. Some research report that the total bile acids concentration was highly variable, and secondary bile acids may well be a factor in carcinogenesis in GBC. These patients with GBC had significantly higher secondary bile acids than the control group $(P<0.05)[16,48]$. There are interesting reports that the 
secondary bile acid DCA does not only cause dysplasia through cytotoxicity, but rather increases the function of carcinogens. For example, tauroursodeoxy cholic acid has been found to promote carcinogenesis of intrahepatic bile duct cancer in hamster models, and taurocholic acid and DCA have been implicated in diisopropanolnitrosamine-induced GBC. Also, the role of secondary bile acids, such as DCA and LCA, together with environmental and genetic factors, is well recognized in colon cancer[49].

Previous studies showed that CACUL1 high expression in cancer tissues was closely related to the survival prognosis of patients, cell cycle regulation, tumor resistance, as well as related to invasion and metastasis[20, 21].Secondary bile acids, a carcinogen closely related to the pathogenesis of colon cancer, can induce the expression of CACUL1, and further promote slug expression, make EMT transformation of cancer cells, and increase the ability of invasion and metastasis of cancer cells. The results showed that CACUL1 expression was higher in cancerous tissue than that in the non-tumor tissues. The prognosis of patients with high expression of CACUL1 was poor. The bioinformatics analysis that CACUL1 was the high expression in Cholangiocarcinoma (CHOL). This suggests that CACUL1 may be closely related to $\mathrm{GBC}$, but there are no relevant research results, which need to be further studied.

Our results showed that CACUL1 was highly expressed in GBC and closely related to metastasis of GBC. In order to clarify the regulatory pathways that CACUL1 may participate in, the differentially expressed genes related to CACUL1 (adj.P value $<0.05$ and $\log F C>2$ or logFC $<2$ ) were screened from GSE105055 in GEO database. ITGBL1 was a positive correlation gene with more than a 10-fold difference in CACUL1-related differentially expressed genes. Currently, information regarding the role and molecular mechanism of ITGBL1 expressed by cancer cells remains limited. In the current study, ITGBL1 expression and its association with clinicopathological features were investigated across a cohort of Chinese GBC patients.

The ITGBL1 protein comprises a typical signal peptide and a hydrophilic 471-amino-acid domain containing ten tandem integrin EGF-like repeats. As an extracellular matrix protein, ITGBL1 was first cloned from HUVEC (human umbilical vein endothelial cells), fetal lung, and osteoblast cDNA libraries. The ITGBL1 protein is highly homologous to the N-terminal EGF-like stalk fragment of integrin $\beta$, but contains neither a transmembrane domain nor an RGD (Arg-Gly-Asp)-binding domain, suggesting that ITGBL1 performs functions distinct from those of integrin[50]. Recently, accumulating evidence indicates that ITGBL1 participates in tumorigenesis and progression by regulating cancer cell proliferation, migration, invasion and angiogenesis. Abnormal ITGBL1 expression has been detected in lung, breast and ovarian cancers, and its expression correlated with cell migration, invasion and cancer metastasis. Recently, few studies have reported the functions of ITGBL1 in human diseases. In gastric cancer, ITGBL1 is a potential biomarker for prognosis and provided evidence that it may influence metastasis and invasion through the KRAS/EMT signaling pathways [24].In breast cancer, ITGBL1 as a Runx2 transcriptional target promotes bone metastasis by activating the TGF $\beta$ signaling pathway[25]; In ovarian cancer, ITGBL1 promotes migration and adhesion through Wnt/PCP (planar cell polarity) and FAK/SRC (focal adhesion kinase/steroid receptor coactivator) signaling pathways [51]. Therefore, the existing literature supports the idea that ITGBL1 functions as an important pro-metastatic oncogene in multiple human cancer types. These evidences implied that ITGBL1 might contribute to the metastasis.

Our results showed that ITGBL1 was highly expressed in GBC and closely related to metastasis of GBC. The prognosis of patients with high expression of ITGBL1 was poor, and CACUL1 was positively correlated with 
ITGBL1. By analyzing the upstream promoter region of ITGBL1, we found that there were NRF2 transcription factor binding sites in the upstream of ITGBL1. CACUL1 could inhibit NRF2 degradation and promoted NRF2 binding to the ITGBL1 promoter region and promoted its expression.Multivariate analysis demonstrated that increased ITGBL1 expression and lymphatic metastasis were independent risk factors in the prognosis of GBC patients. These results suggested that CACUL1 and ITGBL1 may represent novel prognostic markers for GBC patients. The precise molecular mechanisms through which CACUL1 and ITGBL1 impacts GBC invasion and metastasis have yet to be elucidated.

Lymphatic metastasis of GBC is one of the main ways of metastasis and plays a fundamental role during the early steps of GBC invasion, metastasis and relapse [2, 52]. Investigating possible mechanisms modulating malignant cell lymphatic metastasis, GBC cells transfected with ITGBL1 and discovering novel lymphoangiogenesis regulators will further elucidate GBC biology and may provide novel biomarkers and efficient therapeutic targets for GBC. Bioinformatics analysis found that ITGBL1-related downstream pathways are ITGA9(integrin a9) signaling pathways, the results of our analysis revealed that ITGBL1 expression had a positive with correlation the ITGA9 signaling pathway in human GBC specimens, which plays vital roles in the lympho-angiogenesis process of GBC. ITGBL1 could promote the expression of ITGA9. ITGA9 protein binds to integrin $\beta 1$ and thus forms a receptor that interacts with its corresponding ligands present in the extracellular matrix, including VEGF-C[29]. It is important that some researches found that integrin a9 could regulate VEGF expression to promote angiogenesis and lymphangiogenesis via FAK/SRC signaling and its downstream targets, including p-ERK, p38 MAPK, and p-GSK3 $\beta / \beta$-catenin signaling[29-31]. In vitro experiments showed that the expression of VEGF-C was increased in the supernatant of GBC cells transfected with ITGBL1. The results showed that CD34 and D2-40 staining showed that the density of microvascular and lymphatic vessels in nude mice implanted tumors increased significantly compared with the control. In addition, the group transfected with ITGBL1 had a significantly increased risk of metastasis.

\section{Conclusions}

Bacterial infection was one of the factors that cause the decomposition of bile acid salt to produce secondary bile acid salt and inflammatory cytokines were also some of the factors that cause malignant transformation of GBC. Gallstones further aggravate chronic inflammation and can induce transformation, which is further amplified many fold by several toxins and metabolites of known carcinogenic potentials produced by the bacteria. Our results showed suggested that bacterial infection is one of the pathogenesis factors of gallbladder stones and GBC, and bacterial infection and gallstones promote each other, causing the occurrence of GBC, and that the content of inflammatory cytokines in GBC was significantly higher than that in control non-tumor tissues, especially in patients with GBC complicated with bacterial infection or gallstones, the content of inflammatory cytokines is higher. We showed that CACUL1 and ITGBL1 were up-regulated in GBC by immunohistochemistry and PCR, and described CACUL1 and ITGBL1 as crucial factors in the clinical outcomes during human GBC. The highly expressed patients of CACUL1 and ITGBL1 had a poor prognosis, and them therefore might serve as a potential prognostic biomarker for GBC patients. Furthermore, the experimental results showed that CACUL1 could promote the expression of ITGBL1 through NRF2, promote the invasion and metastasis of cancer cells, and ITGBL1 could promote lymphangiogenesis and lymph node metastasis of cancer cells through ITGA9/VEGF-C. These data provide further insight into the pathogenesis of

Page $15 / 34$ 
GBC and provide substantial new evidence that CACUL1 and ITGBL1 may serve as novel prognostic markers and therapeutic targets for GBC.

\section{Materials And Methods}

\section{Patients and histological methods}

We re-examined the gallbladders from 80 GBC patients who underwent surgery from 2012-2017 (mean age: 58 years; range: 32-74 years; 24 male, 56 female), 80 control patients (included 60 gallstone patients, 20 normal gallbladders), composed of liver transplant donors with no biliary disease, liver rupture, liver cancer with no biliary disease were included. There were no obvious macroscopic and pathological abnormalities in the gallbladder specimens resected.(mean age: 52 years; range: 11-77 years; 36 male, 44 female) from 2012 to 2017. These tissues were obtained at the time of laparotomy. These samples were divided into two equal portions. One part of the sample was immediately transferred into liquid nitrogen for DNA and RNA isolation, and the second part was fixed in $10 \%$ buffered formalin solution for the histopathological evaluation. The experiment was conducted with the understanding and written consent of each subject. The research method complies with the stipulated standards set by the Declaration of Helsinki. The study procedure was authorized by the Ethics Committee of Xian Jiaotong University.

\section{Bile sample collection}

Gallbladder bile samples were collected from all patients at the hospital after they were diagnosed with GBC and control. After cholecystectomy, collect at least $1 \mathrm{ml}$ of bile from each patient by gallbladder suction, inject it into a $1.5 \mathrm{~mL}$ epppendorf safety lock tube, and close the lid. For identification of bacterial infections, the samples remained stored at $-80^{\circ} \mathrm{C}$ until processing and testing. Before collection, all patients underwent serum chemistry and complete blood count.

\section{DNA extraction from bile samples}

DNA was extracted from approximately $5 \mathrm{mg}$ of bile samples. To determine whether the bacteria were included, the researchers took two 2-3 mg tablets from each case. According to the manufacturer's instructions, DNA was extracted using the QIAamp DNA Mini Kit Organization Protocol (Qiagen, Hilden, Germany). The extracted DNA was purified using AMPure XP kit (Beckman Coulter, Inc., CA, USA) and quantified using NanoDrop 2000 spectrophotometer (Thermo Fisher Scientific Inc., MA, USA). Combine the extracts $(200 \mu \mathrm{L}$ in total) and extract $5 \mu \mathrm{L}$ of the mixture for PCR analysis.

\section{PCR amplification of Helicobacter DNA}

Next, in order to evaluate the sensitivity of the PCR system for the helicobacter 16S rRNA gene, the following studies were performed. We harvested H.pylori, H.hepaticus, and H.bilis and extracted and quantified bacterial DNA. We then used the amount of $100 \mathrm{ng}$ bacterial DNA and their serial dilutions as a template for the PCR. We prepared five sets of primers: Helicobacter universal, H.pylori, H.hepaticus, and H.bilis. Beginning, all DNA samples were amplified to detect the presence of Helicobacter genus DNA.The DNA extracts were amplified in GeneAmp 2700 Thermocycler (Applied Biosystems, Foster City, CA, USA) and detected by semi nested PCR targeting 16S rDNA of Helicobacter pylori as described above (Supplementary Table 1). 
Subsequently, the samples positive by Helicobacter genus-specific PCR were analyzed to determine the presence of H.pylori, H.hepaticus, and H.bilis. In order to confirm the specificity of the primers, these primers were used to amplify DNA purified from H.pylori, H.hepaticus, and H.bilis.Using Helicobacter genus-specific PCR-positive samples, these primers encoded by H.pylori 16S rRNA, H.hepaticus 16S rRNA and H.bilis 16S rRNA were analyzed (Supplementary Table 1). The following conditions were used for each amplification: $94^{\circ} \mathrm{C} / 1 \mathrm{~min}, 53^{\circ} \mathrm{C} / 1.5 \mathrm{~min}$, and $72^{\circ} \mathrm{C} / 1 \mathrm{~min}$ for 40 cycles for the H.pylori $16 \mathrm{~S}$ rRNA gene; $94^{\circ} \mathrm{C} / 1 \mathrm{~min}, 60^{\circ} \mathrm{C} / 2$ min, and $72^{\circ} \mathrm{C} / 2$ min for 40 cycles for the H.hepaticus $16 \mathrm{~S}$ rRNA gene; and $94^{\circ} \mathrm{C} / 1 \mathrm{~min}, 55^{\circ} \mathrm{C} / 1.5 \mathrm{~min}$, and $72^{\circ} \mathrm{C} / 2.5$ min for 40 cycles for the H.bilis $16 \mathrm{~S}$ rRNA gene.

Five microliters of the PCR products were electrophoretically separated in a $1 \%$ agarose gel containing ethidium bromide and visualized with UV light. Distilled water was used for DNA extraction and PCR solution preparation. When the extracted DNA sample was replaced by distilled water as a negative control, no bands were obtained.

\section{Amplification of non-Helicobacter bacteria}

Enterobacteriaceae, Bacterioides-Prevotella and Enterococcus group-specific PCRs were performed. Except for the annealing temperature, the reaction mixture and amplification conditions for non-Helicobacter PCR detection were the same as the first step of the semi-nested Helicobacter PCR. Except for the annealing temperature, the reaction mixture and amplification conditions of the non- Helicobacter PCR detection are the same as the first step of half-nested Helicobacter PCR.The annealing temperatures and primers used for detection of Enterobacteriaceae, Bacterioides-Prevotella and Enterococcus group were as described before [53] and described (Supplementary Table 1). As positive controls, Escherichia coli (CCUG 17620) was used in all PCR reactions. PCR products were visualized by $1.5 \%$ agarose gel electrophoresis.

\section{Measurement of inflammatory cytokines, including IL-6, TNF- $\alpha$ and TGF- $\beta$ in serum by ELISA}

The blood samples were centrifuged at $3000 \mathrm{rpm}$ for 15 minutes. And the supernatant was collected and stored at $-80^{\circ} \mathrm{C}$ for biochemical analysis. The serum was then used to evaluate the levels of cytokines by commercial enzyme-linked immunosorbent assay (ELISA) kits according to the manufacturer's instructions. Interleukin (IL)-6, tumor necrosis factor (TNF)- $\alpha$ and interleukin (IL)-1 $\beta$ ELISA kits were purchased from Beyotime Biotechnology (Beyotime Biotechnology, Shanghai, China). Subsequently, the IL-6,TNF-a, IL-1 $\beta$ levels

in the sample were measured respectively, according to the manufacturer's protocol. A total of $20 \mu \mathrm{l}$ serum and $80 \mu \mathrm{l}$ sample diluent were added to the wells of a 96-well plate, gently mixed and incubated at $37^{\circ} \mathrm{C}$ for 30 min.Wash the plate 5 times with $100 \mu \mathrm{l}$ of washing buffer, add $100 \mu \mathrm{l}$ of enzyme-labeled reagent after 30 seconds, and incubate at $37^{\circ} \mathrm{C}$ for 30 minutes except for the blank wells. The plate was washed with $100 \mu \mathrm{l}$ washing buffer 5 times for $30 \mathrm{sec}$, and $100 \mu \mathrm{LAB}$ substrate was added at $37^{\circ} \mathrm{C}$ for $15 \mathrm{~min}$. A total of $50 \mu \mathrm{l}$ of stop solution was then added.The absorbance of the resultant yellow colour was determined at $450 \mathrm{~nm}$. These results were calculated by generating a standard curve using a logistic fit of four parameters. All ELISA analysis were carried out using Thermo Scientific Multiskan $\mathrm{FC}^{\mathrm{T}}$, and Skanlt 3.1 software was used for data reduction.

CACUL1, ITGBL1 and NRF2 expression vector construction and transfection 
Stable transfection of cells to up-regulate CACUL1, ITGBL1 and NRF2 expression was performed as previously described. Briefly, CACUL1(NM_153810.5), ITGBL1(NM_001271754.2) and NRF2(NM_001145412.3) were inserted into the pcDNA3.1 (+) mammalian expression vector (Invitrogen, Carlsbad, CA, USA). The cells were seeded in DMEM media containing 10\% fetal bovine serum (GIBCO, Carlsbad, CA, USA). 24 hours later, the cells were transfected with the Transfast ${ }^{\mathrm{T} M}$ Transfection Reagent (Promega, Madison, WI, USA). The ratio of DNA to Transfast $^{\mathrm{TM}}$ Transfection Reagent was1:2. After 1 month of selection with $400 \mu \mathrm{g} / \mathrm{ml} \mathrm{G} 418$ (Sigma-Aldrich, St.Louis, MO, USA), the clones were screened for up-regulation of CACUL1, ITGBL1 and NRF2 expression. The pcDNA3.1 (+) expression vector was used as a negative control.

\section{Cell culture}

The human GBC cell lines SGC-996, GBC-SD, and HEK293T cells were purchased from the Cell Bank of the Chinese Academic of Sciences (Shanghai,China). The cells used in all experiments were in the logarithmic growth phase. These cells were cultured in DMEM media containing 10\% fetal bovine serum (FBS) (GIBCO, Carlsbad, CA, USA) $(\mathrm{pH} 7.4)$ at $37^{\circ} \mathrm{C}$ in a humidified atmosphere containing $5 \% \mathrm{CO}_{2}$, and the culture medium was changed every $2-3 d$.

\section{Cell scratch wounding assay and invasion assay}

In the wound healing test, cells were inoculated into 12 -well plates and cultured at $37^{\circ} \mathrm{C}$ for $24 \mathrm{~h}$, then wounds were created in a single layer of cells using a $10 \mu \mathrm{L}$ pipette tip. The cells were washed to remove cell debris and cultured in DMEM without FBS at $37^{\circ} \mathrm{C}$.Images were taken at different time points following wounding. The wound area was measured by photographing two selected fields at the time of wounding (time 0 ) and $24 \mathrm{~h}$ after wounding. Image J software (NIH, Bethesda, MD, USA) was used to calculate the percentage of wound healing.

The cells transfected with ITGBL1 and control were examined for their invasive ability in vitro in BD BioCoat Matrigel chambers (Transwell, BD Biosciences, San Jose, CA, USA). Briefly, $1 \times 10^{5}$ cells transfected with ITGBL1 and control were seeded into the top chamber with a matrigel coated filter, and $750 \mu$ DMEM containing $5 \%$ fetal bovine serum was used as a chemoattractant. After incubating for 24 hours, removed the non-invasive cells on the upper surface of the membrane, fixed the invasive cells on the lower surface of the membrane, and stained with $5 \%$ crystal violet (Sigma-Aldrich, St.Louis, MO, USA). The number of cells intruded through the matrigel was standardized to those that threaded the non-matrigel to acquire an index of relative percentage of invasion, indicating the invasive ability of cells to in vitro. Cells were counted in five fields for triplicate at 10xmagnification. The cells were photographed through phase-contrast microscopy (Leica Microsystems, Bannockburn, IL).

\section{RNA isolation and RT-PCR}

As earlier described, RNA isolation and RT-PCR were performed.Total RNAs were isolated from cultured cell lines and tissue samples using a Qiazol RNeasy Mini kit (QIAGEN, Maryland, USA). The final volume of the RNA was $50 \mu \mathrm{l}$ and stored at $-80^{\circ} \mathrm{C}$. Agilent Bioanalyzer 2100 (Agilent Technologies, Santa Clara, CA, USA) was used to analyze the purity and integrity of RNA.cDNA was synthesized using PrimeScript ${ }^{\mathrm{TM}} 1 \mathrm{st}$ Strand cDNA Synthesis Kit (Invitrogen, Carlsbad, CA, USA). Gene-specific primers were used to determine the relative amount 
of mRNA.ITGBL1(NM_001271754.2), F: 5'- GGCTGGTATGGGAAGAAGTGT-3'; R: 5'-

CGATCTCCTGGAGGATAGCA-3'. ITGA9(NM_002207.3): F:5'-GACCGCGATGATGAGTGGAT-3'; R: 5'-

CATCAATGGTGGACGGGTGA-3'. CACUL1(NM_153810.5): F:5'- ACATGGGTCGGATTTTCCCC-3'; R: 5'-

AGCAGCTGGTGACAGACATC-3'. Three independent PCR tests were performed from each sample.

\section{Western blotting}

Total protein of GBC tissue and cells was extracted using a total protein extraction buffer (Beyotime, China) and the protein concentration was measured using a BCA Protein Assay Kit (Pierce Biotechnology, US), according to the manufacturer's instructions. Samples were separated by $10 \%$ SDS-PAGE gel electrophoresis and then transferred to nitrocellulose membrane (Millipore, US). Membranes were blocked with 5\% (w/v) nonfat milk (BD, US) in Tris-buffered saline (TBS) and incubated with ITGBL1 antibody (dilution 1:1000, Cat \# PAB20310, rabbit polyclonal antibody, Abnova, USA),CACUL1 antibody [N1C3] (dilution 1:1000, GTX118514, rabbit polyclonal antibody, GeneTex, USA), NRF2 antibody(A-10) (dilution 1:800, sc-365949; mouse monoclonal antibody, Santa Cruz Biotechnology, USA), ITGA9 antibody (dilution 1:800, PA5-103444, rabbit polyclonal antibody, Thermo Scientific, USA), VEGF-C antibody(E-6) (dilution 1:1000, sc-374628, mouse monoclonal antibody, Santa Cruz Biotechnology, USA), $\beta$-actin antibody (C4) (dilution 1:1000, sc-47778, mouse monoclonal antibody, Santa Cruz Biotechnology, USA) antibody diluted in TBS containing 1\% (w/v) bovine serum albumin at $4{ }^{\circ} \mathrm{C}$ overnight. Bound secondary antibodies were detected by Odessey Imaging System (LI-COR Biosciences, Lincoln, NE, USA).

\section{ITGBL1 luciferase reporter gene constructs and luciferase assay}

The region approximately $2.0 \mathrm{~kb}$ upstream from the transcriptional start site of the ITGBL1 was cloned into the pGL3 luciferase vectors (Promega, Madison, WI, USA). The mutants of the ITGBL1 promoter reporter constructs were generated using a QuikChange Site-Directed Mutagenesis Kit (Stratagene, La Jolla, CA, USA). The ITGBL1 luciferase reporter gene constructs or the mutation constructs were cotransfected with the NRF2 plasmid into cells for 48h; pGL3-basic (Promega, Madison, WI, USA) was used as a negative control, while cells transfected with phRL-TK (Renilla luciferase) (Promega, Madison, WI, USA) were used as an internal control. Firefly luciferase activity was normalized to the corresponding Renilla luciferase activity.

Luciferase reporter assay Approximately 8000 HEK293T cells per well were plated into 96-well plates and were co-transfected with 50 ng of the Firefly luciferase reporter and $5 \mathrm{ng}$ of the pRL-CMV Renilla luciferase reporter using Lipofectamine 2000 reagent (Invitrogen; Thermo Fisher Scientific, Inc., Waltham, MA, USA). After 48 hours of incubation, the double luciferase reporter test (Promega, Madison, WI, USA) was used to quantify the activity of firefly and renilla luciferase. The data are expressed as the relative ratio of the firefly luciferase activity to the renilla luciferase activity.

\section{ITGBL1 shRNA transfection}

ITGBL1 shRNA plasmids (psiHIV-U6-shRNA) were obtained from OmicsLink ${ }^{\text {TM }}$ shRNA Expression Clone Datasheet from GeneCopoeia, Inc. ITGBL1-shRNA-transduced cells with particles for shRNA targeting ITGBL1 or a scrambled nontarget negative control were used based on the manufacturer's protocol. The transfection 
process was described above. After 1 month of selection with $2 \mu \mathrm{g} / \mathrm{ml}$ puromycin (Sigma-Aldrich, St. Louis, MO, USA), the clones were screened for downregulation of ITGBL1 expression.

\section{Chromatin immunoprecipitation (ChIP)}

ChIP assays were performed as described previously. Briefly, cells were fixed with $1 \%$ formaldehyde to crosslink the protein and DNA. The chromatin of the samples by ultrasound on ice was sheared into fragments with an average length of about $250 \mathrm{bp}$. Upon sonication, the samples were rotated in a cold microcentrifuge at the highest speed for 12 minutes.

The samples were precleared using a $50 \%$ slurry of protein A/G-Sepharose beads (Sigma-Aldrich Co., Ltd, Poole, Dorset, UK) prepared in immunoprecipitation (IP) buffer for $1 \mathrm{~h}$ at $4^{\circ} \mathrm{C}$. After centrifugation, the supernatant was taken for IP detection. The precleared supernatants were immunoprecipitated overnight at $4^{\circ} \mathrm{C}$ using $10 \mu \mathrm{g}$ anti-NRF2 antibody (H-300): (sc-13032; rabbit polyclonal, Santa Cruz Biotechnology, USA), and normal rabbit IgG antibodies (the negative control). After 3 hours of incubation at $4^{\circ} \mathrm{C}$, the immunoprecipitated DNA/protein complex was combined with protein A/G-Sepharose beads and washed. Proteins were eliminated using proteinase K(200 $\mu$ g; Promega, Madison, WI, USA) in the presence of $10 \%$ SDS by overnight incubation at $37^{\circ} \mathrm{C}$. After phenol extraction, the DNA was precipitated and suspended in water as a template for PCR. Amplify unprecipitated (input) genomic DNA as input control. The PCR products were analyzed on a $2 \%$ agarose gel stained with ethidium bromide.

\section{Immunohistochemical (IHC) staining and scoring}

Gallbladder specimens fixed in 10\% buffered formalin (40\% formaldehyde, sodium dihydrogen phosphate, disodium hydrogen phosphate anhydrous) were processed after $24 \mathrm{~h}$ and embedded in paraffin. 4 micrometerthick sections were cut and stained with hematoxylin-eosin (HE). IHC was performed on paraformaldehydefixed paraffin sections. CACUL1 antibody [N1C3] (dilution 1:400, GTX118514, rabbit polyclonal antibody, GeneTex, USA) and ITGBL1 antibody (dilution 1:400, Cat \# PAB20310, rabbit polyclonal antibody, Abnova, USA) was used in IHC with streptavidin peroxidase-conjugated method. Briefly, deparaffinized sections of formalin-fixed tissues were microwaved (5 min), incubated for $15 \mathrm{~min}$ in $1 \mathrm{mM}$ citrate buffer $(\mathrm{pH} 6.0)$ at $90^{\circ} \mathrm{C}$, treated with $0.3 \%$ hydrogen peroxide in methanol for $20 \mathrm{~min}$ at room temperature to quench endogenous peroxidase activity, incubated with $1 \%$ Bull serum albumin (BSA) in phosphate-buffered saline (PBS) for 30 min to block nonspecific binding sites. The sections were treated and incubated overnight at $4^{\circ} \mathrm{C}$ with diluted in 1\% BSA in PBS primary CACUL1 and ITGBL1 antibodies. The sections were then incubated at room temperature for $1 \mathrm{~h}$ with a peroxidase-coupled IgG (Dianova, Hamburg, Germany) and diluted in $10 \%$ ABO type human blood serum. Following washes, diaminobenzidine was added (Vector Laboratories, Burlingame, CA, USA) to the slides for $5 \mathrm{~min}$, the slides were washed, and the nuclei were counterstained using Harris hematoxylin (Lerner Laboratories, New Haven, CT, USA). The primary antibodies were replaced with PBS or normal serum from the same species as the negative control. The sections were observed and photographed under a microscope (Carl Zeiss, Germany). Immunoreactivity of CACUL1 and ITGBL1 were evaluated according to both the ratio of positive-staining cells and staining intensity. The percentage of positive tumor cells was graded as per the following criteria:,$-<5 \% ;+, 5-25 \% ;++, 25-50 \% ;+++,>50 \%$. Patients with different CACUL1 and ITGBL1 expressions in GBC tissues were divided into the low-expression group (- or + ) and the highexpression group $(++$ or +++$)$. 
Microvascular and lymphatic microvessel density was assessed. IHC stained with CD34 antibody (1:500; sc74499, mouse monoclonal antibody, Santa Cruz, USA) and D2-40 antibody(1:400, sc-166906, mouse monoclonal antibody, Santa Cruz, USA) to analyze the microvascular and lymphatic microvessel density. The endothelial cell or endothelial cell cluster that was separated from adjacent microvascular and lymphatic microvessel, tumor cells, and other connective tissue elements was considered a single, countable microvascular and lymphatic microvessel. Ten microscopic fields $(\times 400)$ were counted for evaluation of microvascular and lymphatic microvessel density in each specimen, and we calculated the mean value of ten microscopic fields for the analyses.

\section{In vivo Assays for Tumor Growth and Metastasis}

The human GBC cell line SGC-996 $\left(1 \times 10^{7}\right)$ transfected with ITGBL1, silTGBL1 and Control were implanted subcutaneously into the flank of nude mice (male BALB/c nu/nu, 4-6 weeks) (Institute of Materia Medica, CAS, Shanghai, China). Tumor growth was monitored with tumor volume, which was calculated as described: $\mathrm{V}\left(\mathrm{mm}^{3}\right)=$ width $^{2}\left(\mathrm{~mm}^{2}\right) \times$ length $(\mathrm{mm}) / 2$. The mice were sacrificed 8 weeks later, and the lungs and tumor nodes were removed. Each lung tissue block was sliced serially and stained with HE. Two pathologists independently calculated and assessed the incidence and classification of lung metastasis.

These sections were made for every tissue block of the tumor nodes and IHC stained with CD34 antibody (1:500; sc-74499, mouse monoclonal antibody, Santa Cruz, USA) and D2-40 antibody (1:400, sc-166906, mouse monoclonal antibody, Santa Cruz, USA) to analysis the microvessel density of tumor nodes. The anesthetic and surgical procedures used, and of peri-operative care were very careful and in line with the ethic standard, that animals did not suffer unnecessarily at any stage of an experiment, whether acute or chronic. These methods were approved by the Animal Care and Use Committee of Xi'an Jiaotong University.

\section{Statistical analysis}

All statistical analyses were done using SPSS 19.0 for windows (IBM Corporation, Armonk, NY, USA) and GraphPad Prism 5 software (San Diego, CA, USA). The Chi-square test and Fisher's exact probability method were used to analyze the correlation between CACUL1 and ITGBL1 expression and clinicopathological parameters in GBC patients. The survival curve was evaluated by Kaplan-Meier method, and the log-rank test was used for analysis. Cox proportional hazards regression model was used to conduct univariate and multivariate analysis to identify the factors that have a significant influence on survival. $\mathrm{P}<0.05$ was considered statistically significant.

\section{Abbreviations}




\begin{tabular}{|ll|}
\hline GBC & Gallbladder cancer \\
\hline LNM & lymph node metastases \\
\hline DCA & deoxycholic acid \\
\hline LCA & lithocholic acid \\
\hline ELISA & enzyme-linked immunosorbent assay \\
\hline IL-6 & Interleukin-6 \\
\hline TNF-a & tumor necrosis factor-a \\
\hline IL-1 $\beta$ & interleukin -1 $\beta$ \\
\hline FBS & fetal bovine serum \\
\hline IP & immunoprecipitation \\
\hline IHC & Immunohistochemical \\
\hline HE & hematoxylin-eosin \\
\hline BSA & Bull serum albumin \\
\hline PBS & phosphate-buffered saline \\
\hline ECM & extracellular matrix \\
\hline GEPIA & Gene Expression Profiling Interactive Analysis \\
\hline ENCORI & The Encyclopedia of RNA Interactomes \\
\hline CHOL & Cholangiocarcinoma \\
\hline HUVEC & human umbilical vein endothelial cells \\
\hline
\end{tabular}

\section{Declarations}

\section{Acknowledgements}

This work was supported by the Shannxi Provincial Science and Technology Plan for 2020 (NO. 2020JM-369). We thank all the participants for their contributions to the study.

\section{Funding}

This work was supported by the Shannxi Provincial Science and Technology Plan for 2020 (NO. 2020JM-369). We thank all the participants for their contributions to the study.

\section{Data Availability Statement}

The datasets generated for this study are available on request to the corresponding authors. 
The study was reviewed and approved by the Ethics Committee of First Hospital of Xi'an Jiaotong University. A written informed consent was obtained from each patient.

\section{Consent for publication}

The authors have agreed to publish this research article in your journal.

\section{Author Contributions}

YK, and ALS performed and designed experiments, analyzed, and interpreted data, and wrote the manuscript. $\mathrm{KW}$, and ALS performed the experiments. All authors contributed to the article and approved the submitted version.

\section{Conflict of interest}

The authors declare that the research was conducted in the absence of any commercial or financial relationships that could be construed as a potential conflict of interest.

\section{References}

1. Berger-Richardson D, Chesney TR, Englesakis M, Govindarajan A, Cleary SP, Swallow CJ. Trends in port-site metastasis after laparoscopic resection of incidental gallbladder cancer: A systematic review. Surgery. 2017;161(3):618-27.

2. Jiang L, Liu M, Cai X, Xie L, She F, Chen Y. Serum vascular endothelial growth factor-C levels predict lymph node metastasis and prognosis of patients with gallbladder cancer. Oncol Lett. 2018;16(5):6065-70.

3. Cha BH. Epidemiological Characteristics of Gallbladder Cancer in Jeju Island: A Single-Center, Clinically Based, Age-Sex-Matched, Case-Control Study. Asian Pac J Cancer Prev. 2015;16(18):8451-4.

4. Li Y, Zhang J, Ma H. Chronic inflammation and gallbladder cancer. Cancer Lett. 2014;345(2):242-8.

5. Poojary SS, Mishra G, Gupta S, Shrivastav BR, Tiwari PK. Dysfunction of subtelomeric methylation and telomere length in gallstone disease and gallbladder cancer patients of North Central India. J Hepatobiliary Pancreat Sci. 2016;23(5):276-82.

6. Chen W, Li D, Cannan RJ, Stubbs RS. Common presence of Helicobacter DNA in the gallbladder of patients with gallstone diseases and controls. Dig Liver Dis. 2003;35(4):237-43.

7. Mishra RR, Tewari M, Shukla HS. Helicobacter pylori and pathogenesis of gallbladder cancer. J Gastroenterol Hepatol. 2011;26(2):260-6.

8. Randi G, Franceschi S, La Vecchia C. Gallbladder cancer worldwide: geographical distribution and risk factors. Int J Cancer. 2006;118(7):1591-602.

9. Tewari M, Mishra RR, Shukla HS. Salmonella typhi and gallbladder cancer: report from an endemic region. Hepatobiliary Pancreat Dis Int. 2010;9(5):524-30.

10. Mishra RR, Tewari M, Shukla HS. Helicobacter species and pathogenesis of gallbladder cancer. Hepatobiliary Pancreat Dis Int. 2010;9(2):129-34. 
11. Mishra RR, Tewari M, Shukla HS. Association of Helicobacter pylori infection with inflammatory cytokine expression in patients with gallbladder cancer. Indian J Gastroenterol. 2013;32(4):232-5.

12. Maurer KJ, Ihrig MM, Rogers AB, Ng V, Bouchard G, Leonard MR, Carey MC, Fox JG. Identification of cholelithogenic enterohepatic helicobacter species and their role in murine cholesterol gallstone formation. Gastroenterology. 2005;128(4):1023-33.

13. Pandey M, Mishra RR, Dixit R, Jaiswal R, Shukla M, Nath G. Helicobacter bilis in human gallbladder cancer: results of a case-control study and a meta-analysis. Asian Pac J Cancer Prev. 2010;11(2):343-7.

14. Koshiol J, Gao YT, Corbel A, Kemp TJ, Shen MC, Hildesheim A, Hsing AW, Rashid A, Wang B, Pfeiffer RM, et al. Circulating inflammatory proteins and gallbladder cancer: Potential for risk stratification to improve prioritization for cholecystectomy in high-risk regions. Cancer Epidemiol. 2018;54:25-30.

15. Guo R, Qin Y, Shi P, Xie J, Chou M, Chen Y. IL-1 beta promotes proliferation and migration of gallbladder cancer cells via Twist activation. Oncol Lett. 2016;12(6):4749-55.

16. Park JY, Park BK, Ko JS, Bang S, Song SY, Chung JB. Bile acid analysis in biliary tract cancer. Yonsei Med J. 2006;47(6):817-25.

17. Funabiki T, Sugiue $K$, Matsubara T, Amano H, Ochiai M. Bile acids and biliary carcinoma in pancreaticobiliary maljunction. Keio J Med. 1991;40(3):118-22.

18. Makino T, Obara T, Ura H, Kinugasa T, Kobayashi H, Takahashi S, Konishi Y. Effects of phenobarbital and secondary bile acids on liver, gallbladder, and pancreas carcinogenesis initiated by N-nitrosobis (2hydroxypropyl)amine in hamsters. J Natl Cancer Inst. 1986;76(5):967-75.

19. Shimada K, Chijiiwa K, Yanagisawa J, Nakayama F. Biliary bile acids in the gall-bladder and the common bile duct of patients with anomalous pancreaticobiliary ductal junction. J Gastroenterol Hepatol. 1993;8(2):138-41.

20. Kong Y, Ma LQ, Bai PS, Da R, Sun H, Qi XG, Ma JQ, Zhao RM, Chen NZ, Nan KJ. Helicobacter pylori promotes invasion and metastasis of gastric cancer cells through activation of AP-1 and up-regulation of CACUL1. Int J Biochem Cell Biol. 2013;45(11):2666-78.

21. Kigoshi Y, Fukuda T, Endo T, Hayasaka N, lemura S, Natsume T, Tsuruta F, Chiba T: CACUL1/CAC1 Regulates the Antioxidant Response by Stabilizing Nrf2. Sci Rep 2015, 5:12857.

22. Fukuda T, Kigoshi-Tansho Y, Naganuma T, Kazaana A, Okajima T, Tsuruta F, Chiba T. CACUL1/CAC1 attenuates p53 activity through PML post-translational modification. Biochem Biophys Res Commun. 2017;482(4):863-9.

23. Gan X, Liu Z, Tong B, Zhou J. Epigenetic downregulated ITGBL1 promotes non-small cell lung cancer cell invasion through Wnt/PCP signaling. Tumour Biol. 2016;37(2):1663-9.

24. Li R, Zhuang C, Jiang S, Du N, Zhao W, Tu L, Cao H, Zhang Z, Chen X. ITGBL1 Predicts a Poor Prognosis and Correlates EMT Phenotype in Gastric Cancer. J Cancer. 2017;8(18):3764-73.

25. Li XQ, Du X, Li DM, Kong PZ, Sun Y, Liu PF, Wang QS, Feng YM. ITGBL1 Is a Runx2 Transcriptional Target and Promotes Breast Cancer Bone Metastasis by Activating the TGFbeta Signaling Pathway. Cancer Res. 2015;75(16):3302-13.

26. Bazigou E, Xie S, Chen C, Weston A, Miura N, Sorokin L, Adams R, Muro AF, Sheppard D, Makinen T. Integrin-alpha9 is required for fibronectin matrix assembly during lymphatic valve morphogenesis. Dev 
Cell. 2009;17(2):175-86.

27. Huang B, Niu Y, Chen Z, Yang Y, Wang X. Integrin alpha9 is involved in the pathopoiesis of acute aortic dissection via mediating phenotype switch of vascular smooth muscle cell. Biochem Biophys Res Commun. 2020;533(3):519-25.

28. Ito K, Morimoto J, Kihara A, Matsui Y, Kurotaki D, Kanayama M, Simmons S, Ishii M, Sheppard D, Takaoka A, et al. Integrin alpha9 on lymphatic endothelial cells regulates lymphocyte egress. Proc Natl Acad Sci U S A. 2014;111(8):3080-5.

29. Vlahakis NE, Young BA, Atakilit A, Sheppard D. The lymphangiogenic vascular endothelial growth factors VEGF-C and -D are ligands for the integrin alpha9beta1. J Biol Chem. 2005;280(6):4544-52.

30. Gupta SK, Oommen S, Aubry MC, Williams BP, Vlahakis NE. Integrin alpha9beta1 promotes malignant tumor growth and metastasis by potentiating epithelial-mesenchymal transition. Oncogene. 2013;32(2):141-50.

31. Gupta SK, Vlahakis NE. Integrin alpha9beta1 mediates enhanced cell migration through nitric oxide synthase activity regulated by Src tyrosine kinase. J Cell Sci. 2009;122(Pt 12):2043-54.

32. Li JH, Liu S, Zhou H, Qu LH, Yang JH. starBase v2.0: decoding miRNA-ceRNA, miRNA-ncRNA and proteinRNA interaction networks from large-scale CLIP-Seq data. Nucleic Acids Res. 2014;42(Database issue):D92-7.

33. Szklarczyk D, Gable AL, Lyon D, Junge A, Wyder S, Huerta-Cepas J, Simonovic M, Doncheva NT, Morris JH, Bork P, et al. STRING v11: protein-protein association networks with increased coverage, supporting functional discovery in genome-wide experimental datasets. Nucleic Acids Res. 2019;47(D1):D607-13.

34. Espinoza JA, Bizama C, Garcia P, Ferreccio C, Javle M, Miquel JF, Koshiol J, Roa JC. The inflammatory inception of gallbladder cancer. Biochim Biophys Acta. 2016;1865(2):245-54.

35. Srivastava A, Sharma KL, Srivastava N, Misra S, Mittal B. Significant role of estrogen and progesterone receptor sequence variants in gallbladder cancer predisposition: a multi-analytical strategy. PLoS One. 2012;7(7):e40162.

36. Hong H, Jiang L, Lin Y, He C, Zhu G, Du Q, Wang X, She F, Chen Y. TNF-alpha promotes lymphangiogenesis and lymphatic metastasis of gallbladder cancer through the ERK1/2/AP-1/VEGF-D pathway. BMC Cancer. 2016;16:240.

37. Jain K, Sreenivas V, Velpandian T, Kapil U, Garg PK. Risk factors for gallbladder cancer: a case-control study. Int J Cancer. 2013;132(7):1660-6.

38. Sharma RK, Sonkar K, Sinha N, Rebala P, Albani AE, Behari A, Reddy DN, Farooqui A, Kapoor VK. Gallstones: A Worldwide Multifaceted Disease and Its Correlations with Gallbladder Carcinoma. PLoS One. 2016;11(11):e0166351.

39. Roa I, de Aretxabala X, Araya JC, Roa J. Preneoplastic lesions in gallbladder cancer. J Surg Oncol. 2006;93(8):615-23.

40. Jain K, Mohapatra T, Das P, Misra MC, Gupta SD, Ghosh M, Kabra M, Bansal VK, Kumar S, Sreenivas V, et al. Sequential occurrence of preneoplastic lesions and accumulation of loss of heterozygosity in patients with gallbladder stones suggest causal association with gallbladder cancer. Ann Surg. 2014;260(6):107380 . 
41. Mathur SK, Duhan A, Singh S, Aggarwal M, Aggarwal G, Sen R, Singh S, Garg S. Correlation of gallstone characteristics with mucosal changes in gall bladder. Trop Gastroenterol. 2012;33(1):39-44.

42. Nevin JE, Moran TJ, Kay S, King R. Carcinoma of the gallbladder: staging, treatment, and prognosis. Cancer. 1976;37(1):141-8.

43. de Martel C, Plummer M, Parsonnet J, van Doorn LJ, Franceschi S. Helicobacter species in cancers of the gallbladder and extrahepatic biliary tract. Br J Cancer. 2009;100(1):194-9.

44. Tsuchiya Y, Loza E, Villa-Gomez G, Trujillo CC, Baez S, Asai T, Ikoma T, Endoh K, Nakamura K. Metagenomics of Microbial Communities in Gallbladder Bile from Patients with Gallbladder Cancer or Cholelithiasis. Asian Pac J Cancer Prev. 2018;19(4):961-7.

45. Murata H, Tsuji S, Tsujii M, Fu HY, Tanimura H, Tsujimoto M, Matsuura N, Kawano S, Hori M. Helicobacter bilis infection in biliary tract cancer. Aliment Pharmacol Ther. 2004;20(Suppl 1):90-4.

46. Narayan RR, Creasy JM, Goldman DA, Gonen M, Kandoth C, Kundra R, Solit DB, Askan G, Klimstra DS, Basturk $\mathrm{O}$, et al. Regional differences in gallbladder cancer pathogenesis: Insights from a multiinstitutional comparison of tumor mutations. Cancer. 2019;125(4):575-85.

47. Matsukura N, Yokomuro S, Yamada S, Tajiri T, Sundo T, Hadama T, Kamiya S, Naito Z, Fox JG. Association between Helicobacter bilis in bile and biliary tract malignancies: $\mathrm{H}$. bilis in bile from Japanese and Thai patients with benign and malignant diseases in the biliary tract. Jpn J Cancer Res. 2002;93(7):842-7.

48. Hsing AW, Gao YT, Han TQ, Rashid A, Sakoda LC, Wang BS, Shen MC, Zhang BH, Niwa S, Chen J, et al. Gallstones and the risk of biliary tract cancer: a population-based study in China. $\mathrm{Br} \mathrm{J}$ Cancer. 2007;97(11):1577-82.

49. Tocchi A, Basso L, Costa G, Lepre L, Liotta G, Mazzoni G, Sita A, Tagliacozzo S. Is there a causal connection between bile acids and colorectal cancer? Surg Today. 1996;26(2):101-4.

50. Qiu X, Feng JR, Qiu J, Liu L, Xie Y, Zhang YP, Liu J, Zhao Q. ITGBL1 promotes migration, invasion and predicts a poor prognosis in colorectal cancer. Biomed Pharmacother. 2018;104:172-80.

51. Sun L, Wang D, Li X, Zhang L, Zhang H, Zhang Y. Extracellular matrix protein ITGBL1 promotes ovarian cancer cell migration and adhesion through Wnt/PCP signaling and FAK/SRC pathway. Biomed Pharmacother. 2016;81:145-51.

52. Lin W, Jiang L, Chen Y, She F, Han S, Zhu J, Zhou L, Tang N, Wang X, Li X. Vascular endothelial growth factor-D promotes growth, lymphangiogenesis and lymphatic metastasis in gallbladder cancer. Cancer Lett. 2012;314(2):127-36.

53. Karagin PH, Stenram U, Wadstrom T, Ljungh A. Helicobacter species and common gut bacterial DNA in gallbladder with cholecystitis. World J Gastroenterol. 2010;16(38):4817-22.

\section{Figures}


a

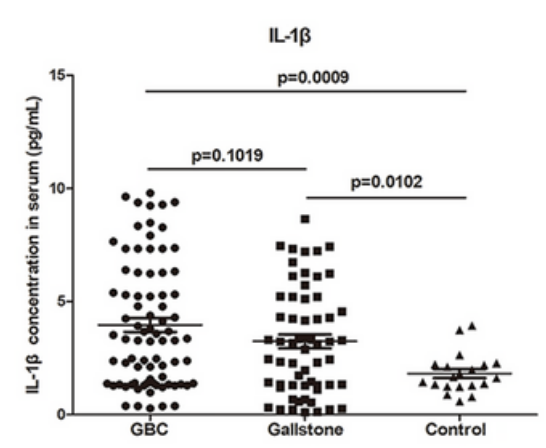

b

C

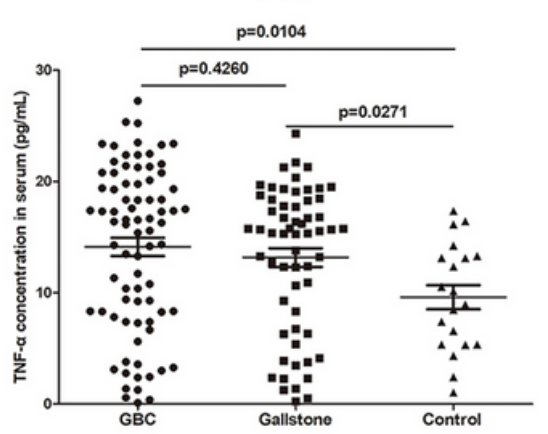

d

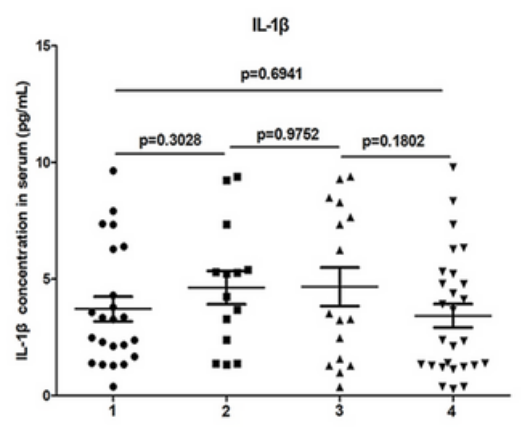

e
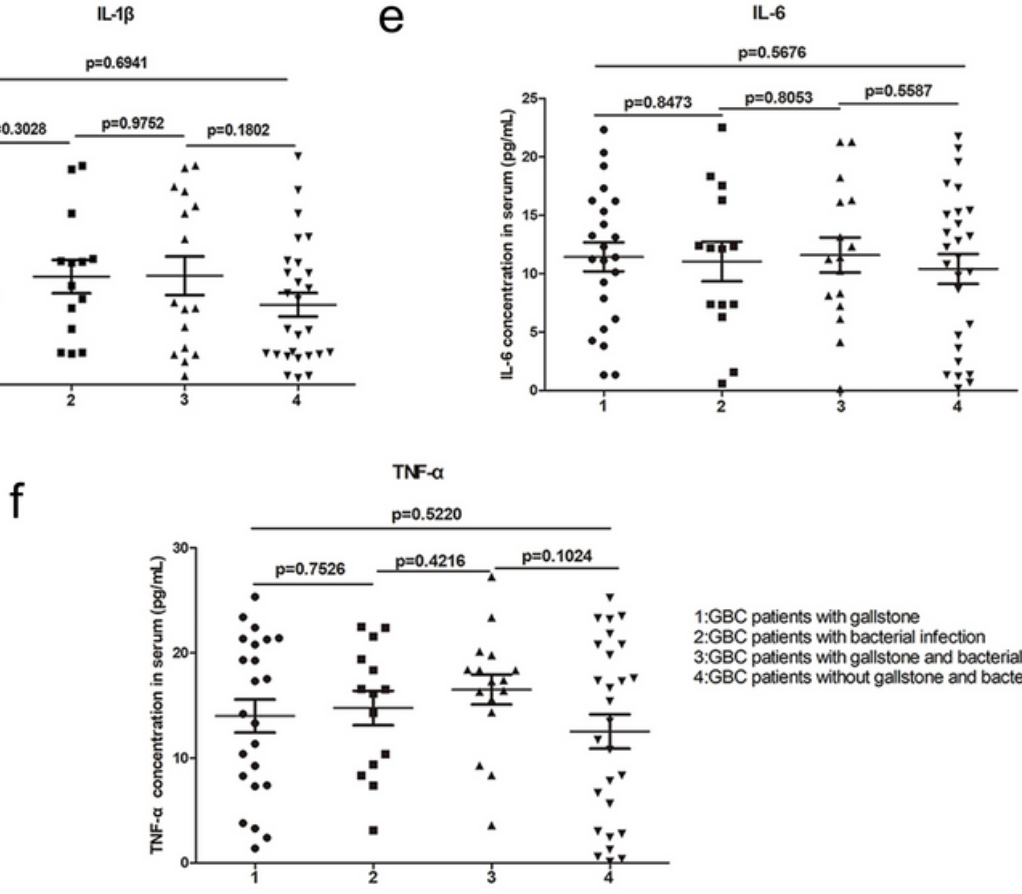

1:GBC patients with gallstone

:GBC patients with bacterial infection

GBC patients with gallstone and bacterial infection

4:GBC patients without gallstone and bacterial infection

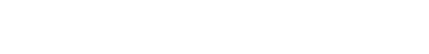

\section{Figure 1}

The levels of IL-1 $\beta$, IL- 6 , and TNF- $a$ in serum. $a, b, c$ The levels of IL-1 $\beta$, IL- 6 , and TNF- $\alpha$ of GBC groups and gallstone groups were observably increased compared to the normal groups. IL-1 $\beta$, IL-6, and TNF- $\alpha$ levels were no significant difference between GBC and gallstone groups. d,e,f GBC patients were subdivided into GBC patients with gallstone(1); GBC patients with bacterial infection(2); GBC patients with gallstone and bacterial infection(3) and GBC patients without gallstone and bacterial infection(4). Among GBC patients with different condition, the levels of inflammation cytokines were no significant difference. 
a

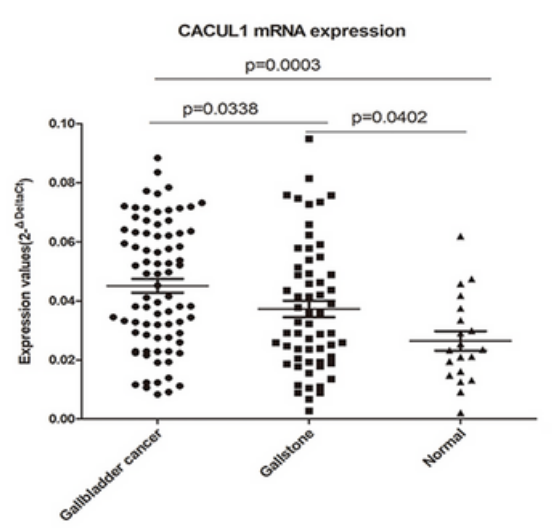

C

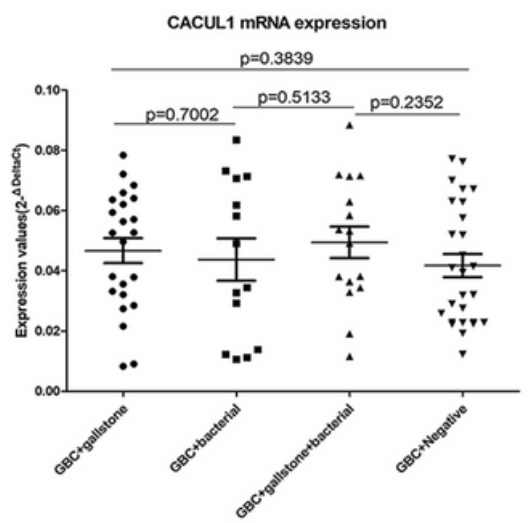

b

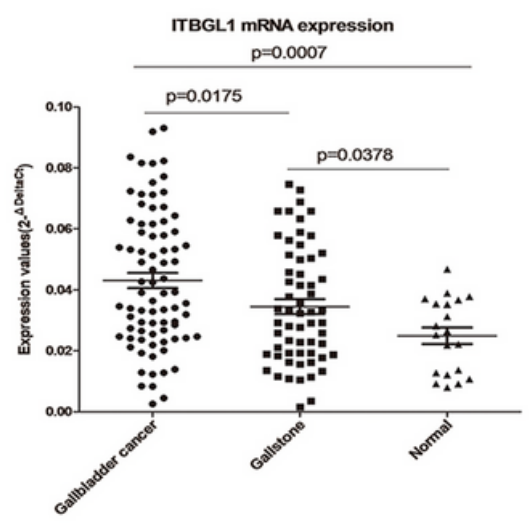

d

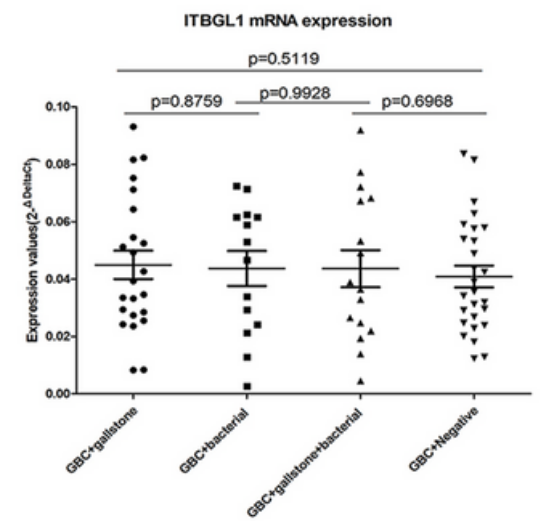

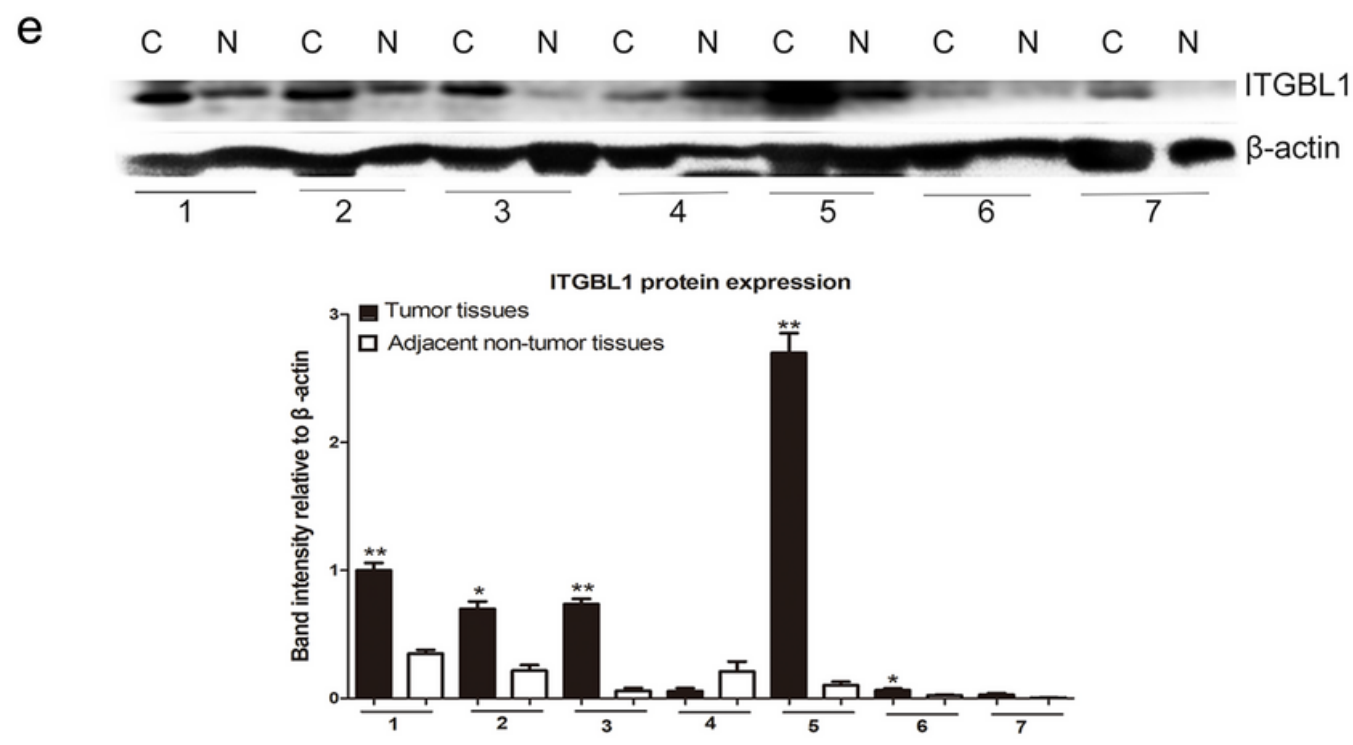

Figure 2

The expression of CACUL1 and ITGBL1 up-regulated in GBC tissues. a,b The expression levels of CACUL1 and ITGBL1 mRNA was significantly increased in GBC tissues comparing with gallstone and normal tissues. c,d The expression levels of CACUL1 and ITGBL1 mRNA was no significant difference among GBC groups with different condition.e the protein expression of ITGBL1 in another 7 pairs of resected tumor tissues and paired adjacent non-tumor tissues from GBC patients was used by western blotting analysis. The expression of ITGBL1 was increased in GBC tissues compared with the paired adjacent non-tumor tissues. $*, P<0.05$, **, $\mathrm{P}<$ 0.01 . 


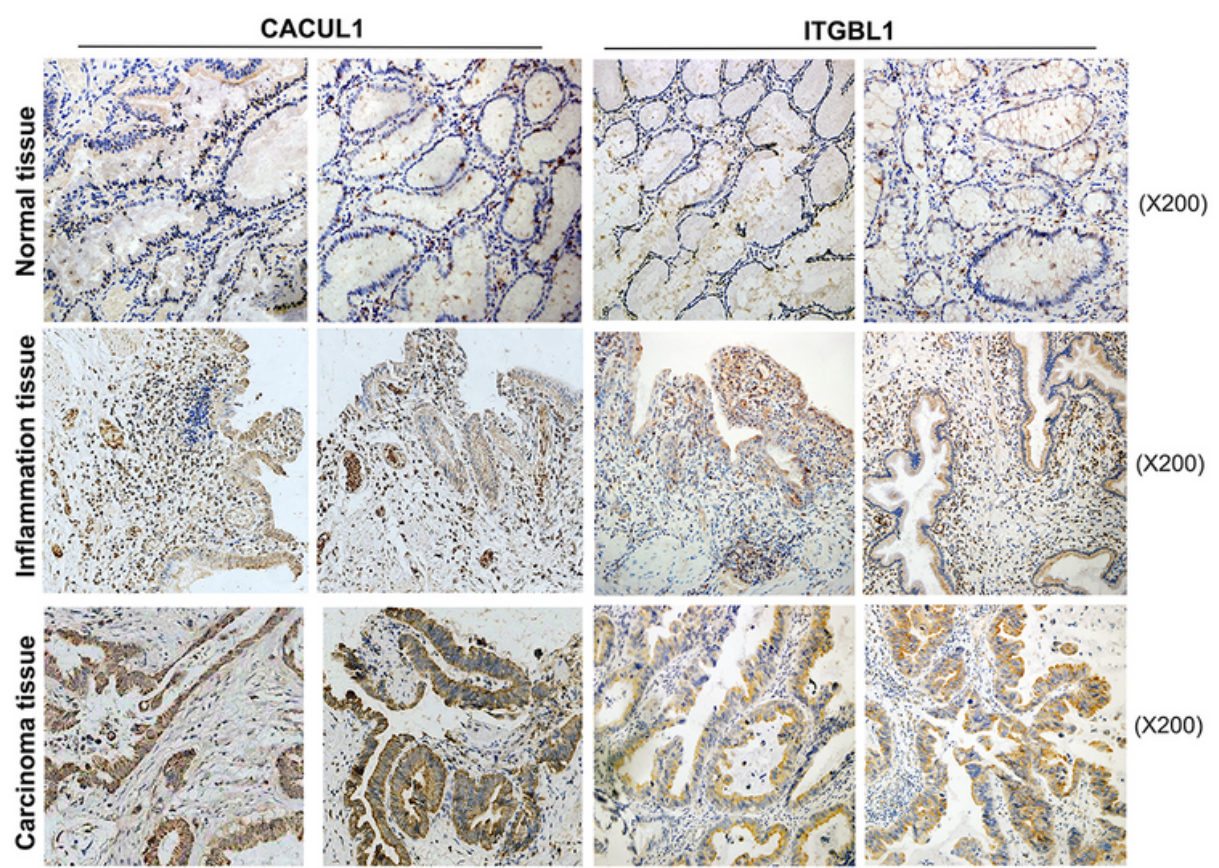

b

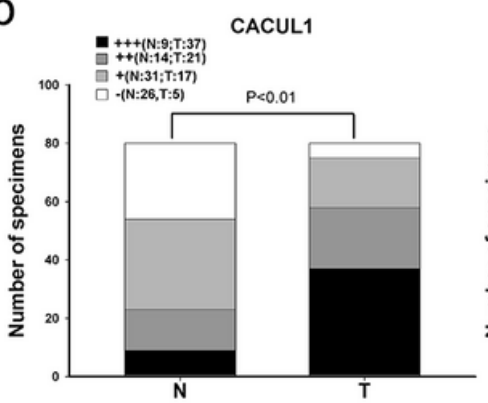

d

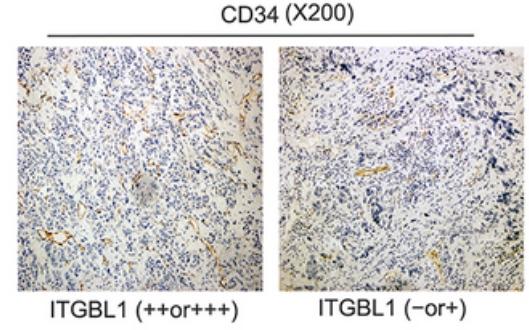

C

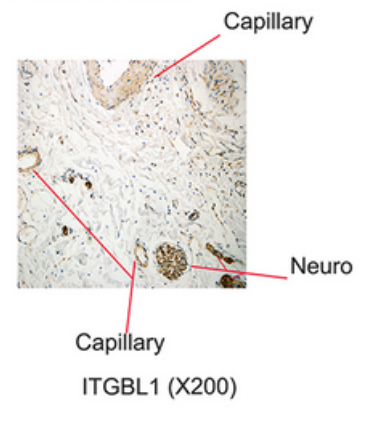

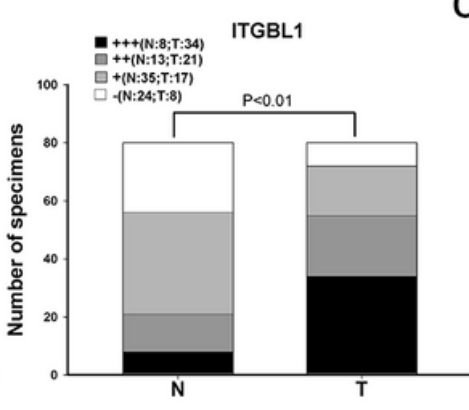

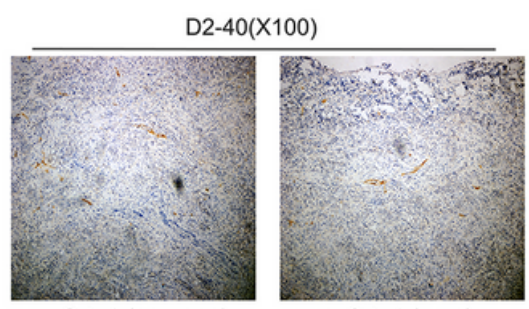

ITGBL1 (++or+++)

ITGBL1 (-or+)

\section{Figure 3}

IHC analysis for CACUL1 and ITGBL1 was performed in GBC, inflammation and normal tissues. a The positive immunostaining for CACUL1 was predominantly observed in the cytoplasm and extracellular matrix (ECM). $b$ We found that CACUL1 and ITGBL1 were significantly up-regulated in GBC tissues compared with non-tumor tissues. c The positive immunostaining for ITGBL1 was also predominantly observed in the cytoplasm, ECM, nerve tract and capillary of GBC and non-tumor tissues. $d$ The positive immunostaining of CD34, D2-40 for microvascular and lymphatic microvessel. The microvascular and lymphatic microvessel density was 
increased in the high expression of ITGBL1 groups(++ or +++) compared with the low expressions of ITGBL1 groups(- or+).

a

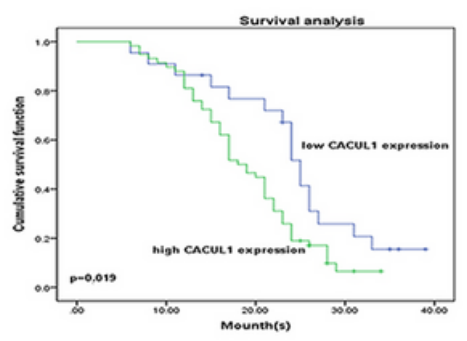

b

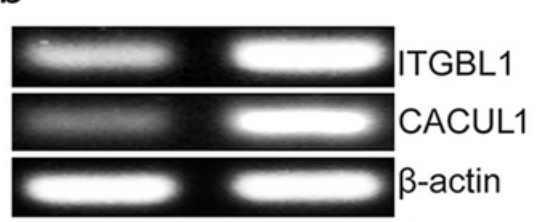

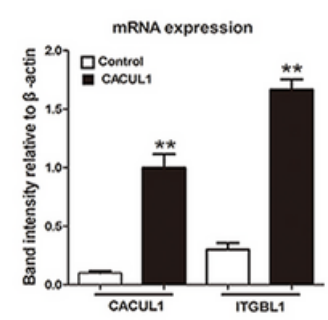

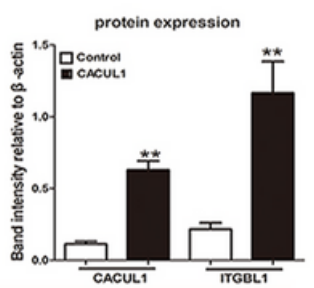

f

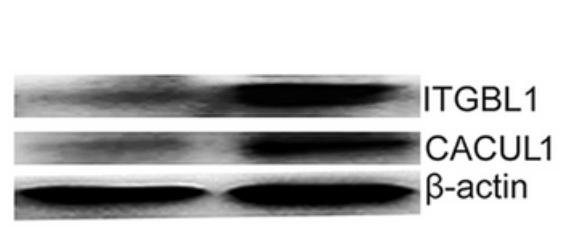

C
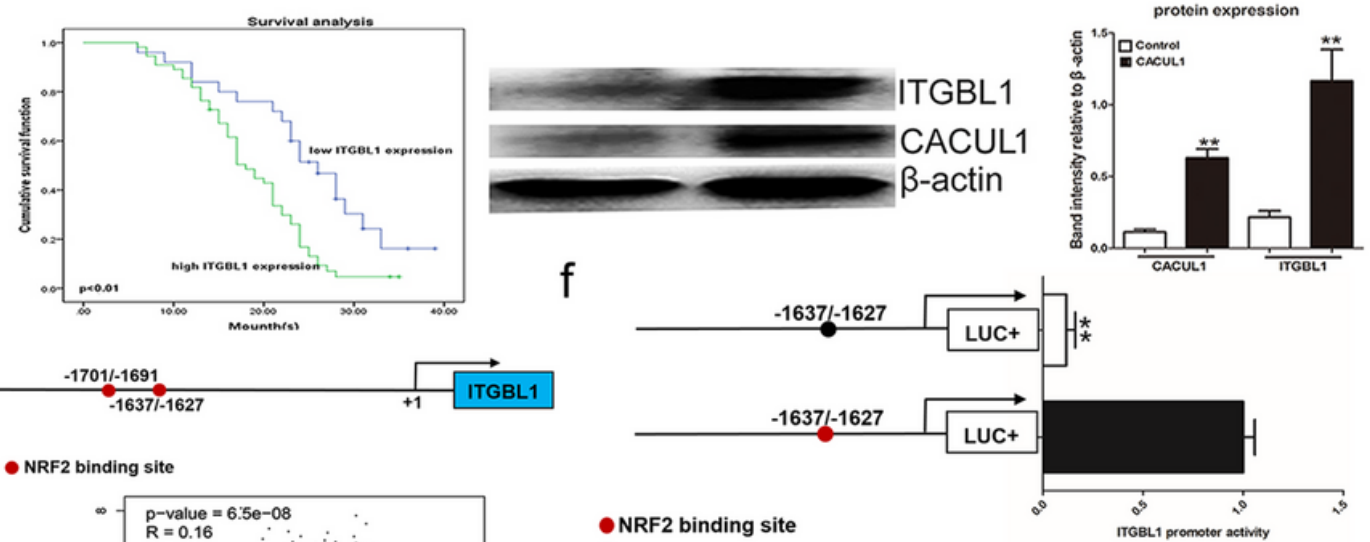

d

- NRF2 binding site

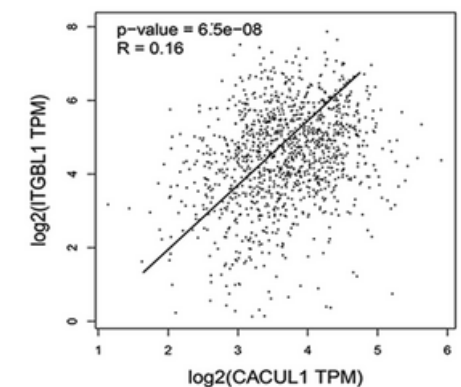

g

- Mutated NRF2 binding site
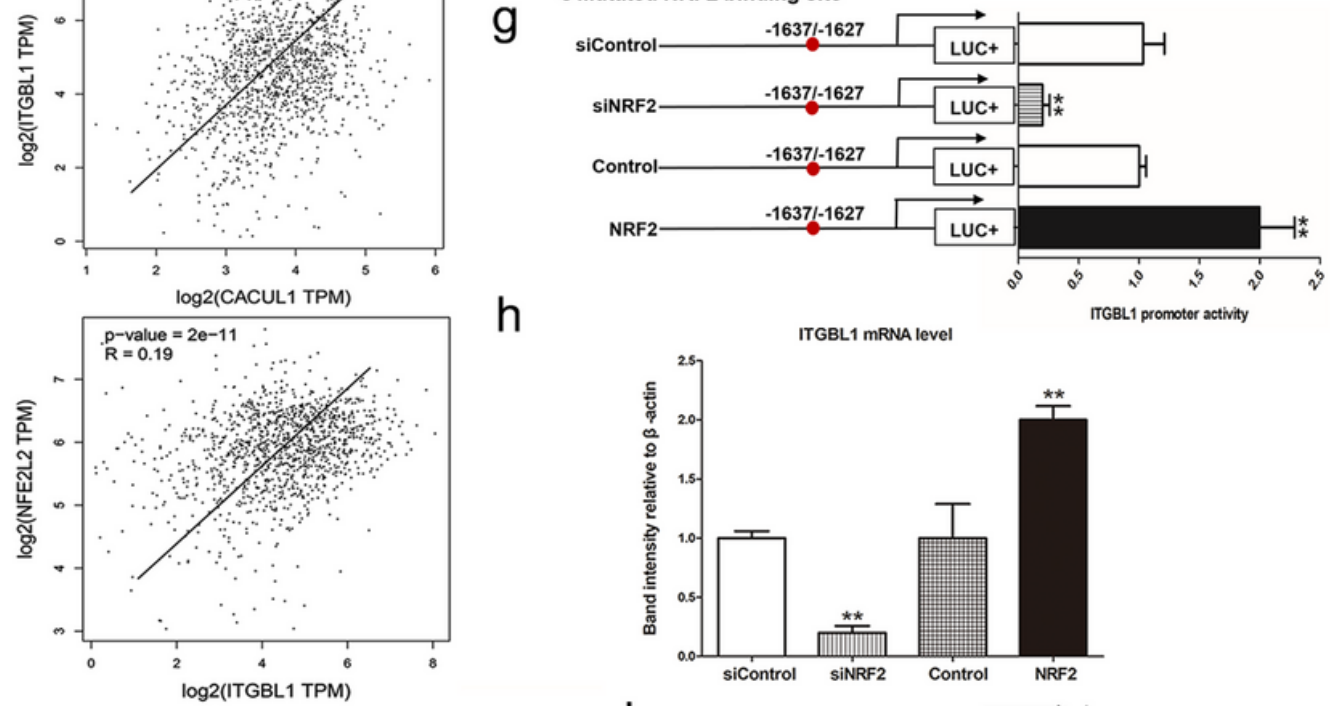

$\mathrm{h}$

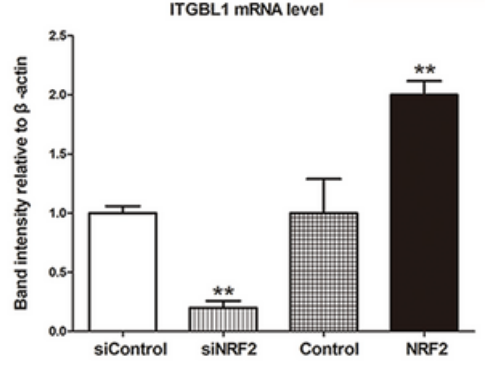

e
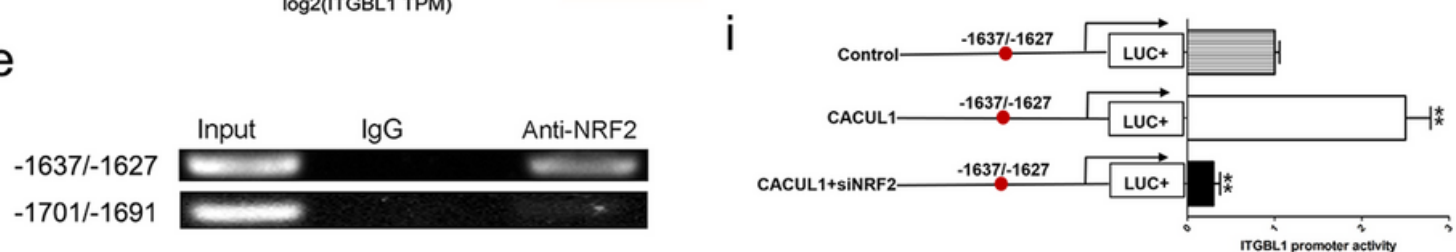

\section{Figure 4}

ITGBL1 is a target gene of the transcription factor NRF2. a The high CACUL1 and ITGBL1 group had significantly poorer overall survival than the low CACUL1 and ITGBL1 group. b CACUL 1 upregulated the expression of ITGBL1. c The schematic showing the potential NRF2-binding sites in the ITGBL1 promoter. $d$ The bioinformatics analysis that ITGBL1 was the positive relationship and co-expressed with CACUL1 and NRF2 in GEPIA database. e The recruitment of NRF2 to the promoter of ITGBL1 in NRF2-overexpressing cells 
was detected by ChIP using anti-NRF2 antibody, and found that NRF2 strong bound the ITGBL1 promoter region containing the -1637/-1627 site, but very weakly combined with -1701/-1691 site. f ITGBL1 promoter activity decreased in the cells transfected with pGL3-ITGBL1 -1637/-1627 with a mutated NRF2-binding motif compared with the control cells transfected with pGL3-ITGBL1-1637/-1627 with the wild-type NRF2-binding motif. g NRF2 overexpression enhanced the activity of ITGBL1 promoter compared with their respective control cells. $\mathrm{h}$ The ITGBL1 mRNA expression level was downregulated in shRNA-mediated NRF2 cells and upregulated in NRF2-overexpressing cells compared with their respective control cells. i CACUL1 promotes NRF2 binding to the promoter region of ITGBL1, whereas silencing NRF2 attenuated the upregulation of ITGBL1 induced by CACUL1. *, P $<0.05, * *, P<0.01$.

a

Oh
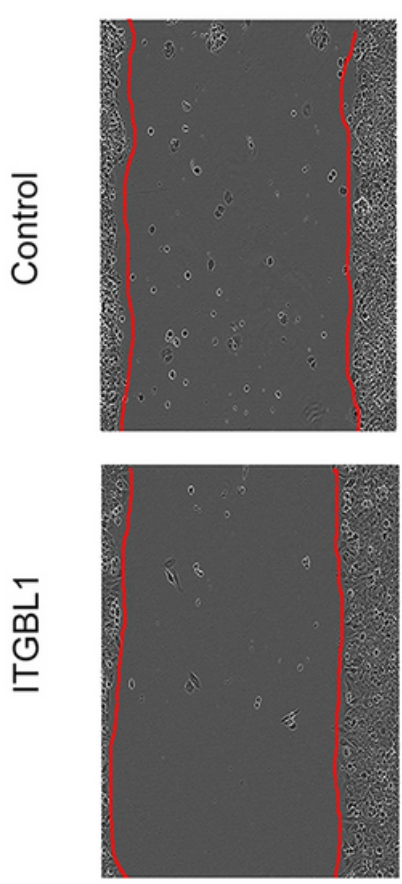

b
$12 \mathrm{~h}$
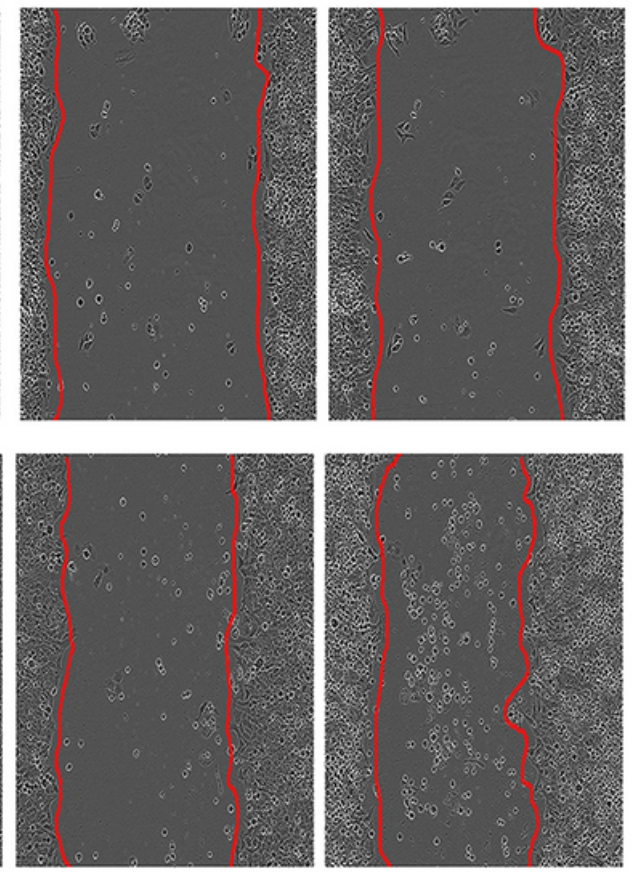

$24 \mathrm{~h}$

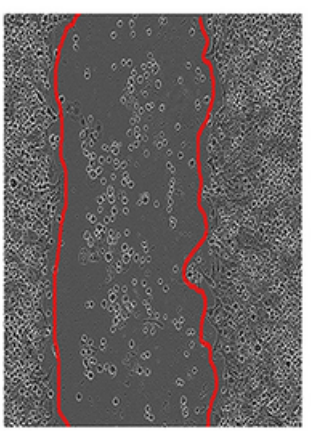

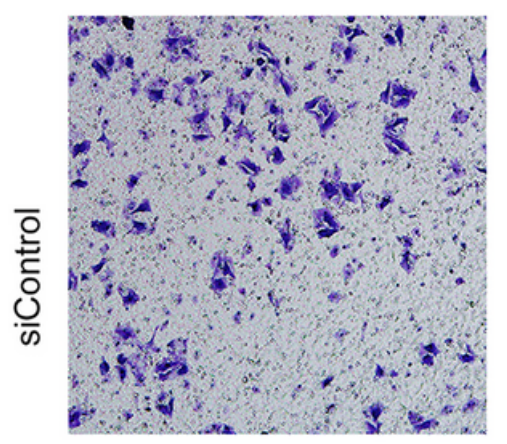
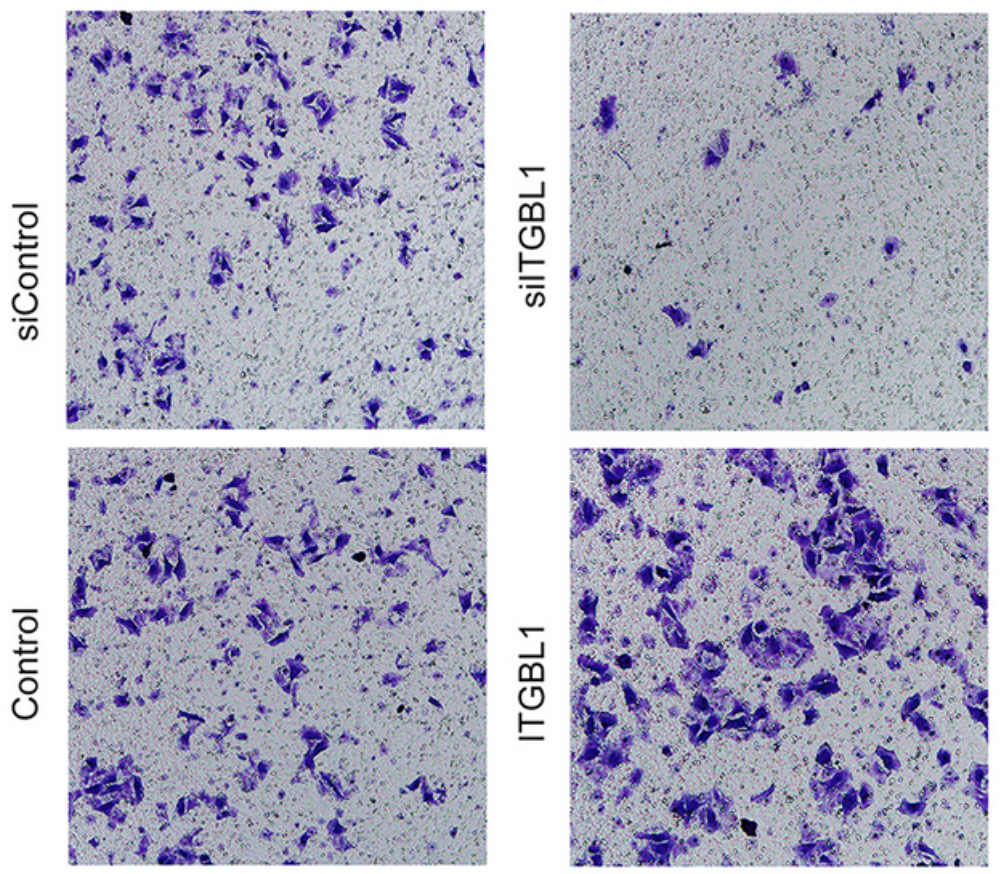
Figure 5

ITGBL1 promotes cell migration and invasion in vitro. a The more cells transfected with ITGBL1 had moved into the scratch wound than NC transfected cells. $b$ The overexpression of ITGBL1 promoted the invasion of cells, and the inhibition of ITGBL1 expression decreased the invasion potential of cells.

a

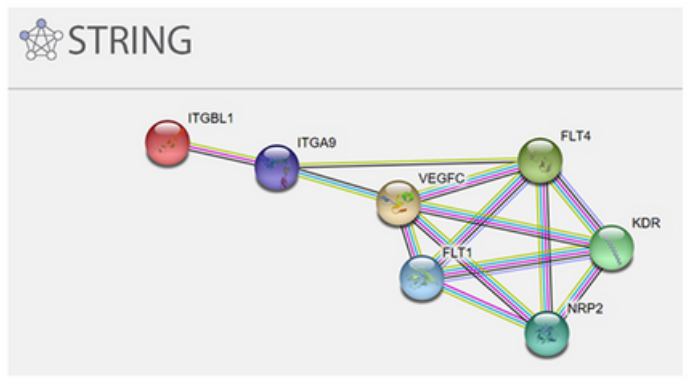

C
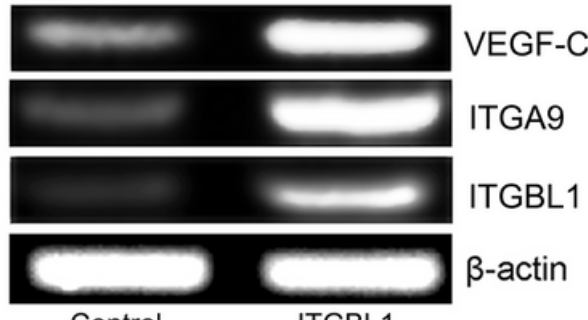

Control ITGBL1

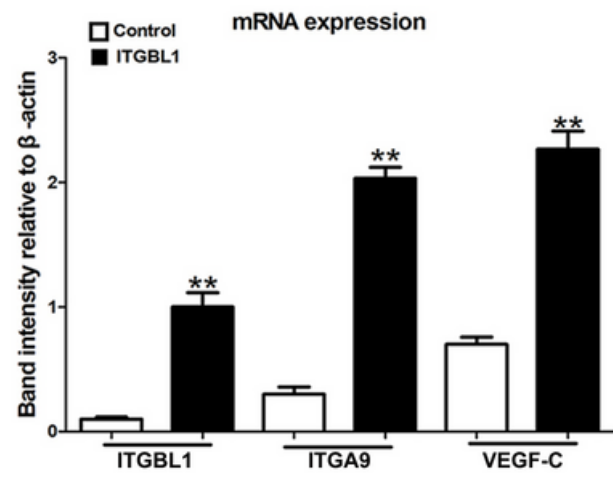

e

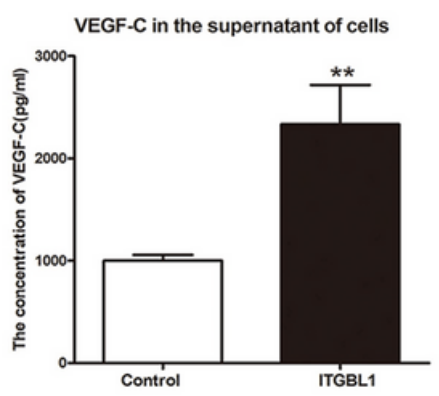

b

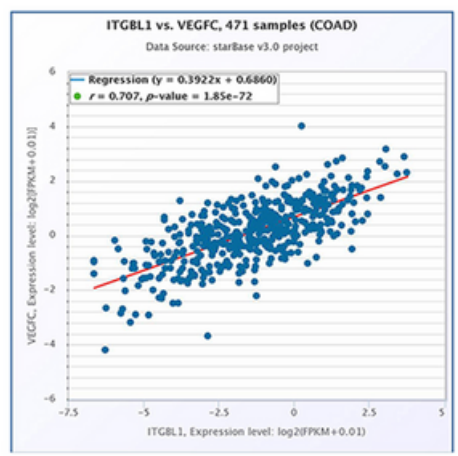

d
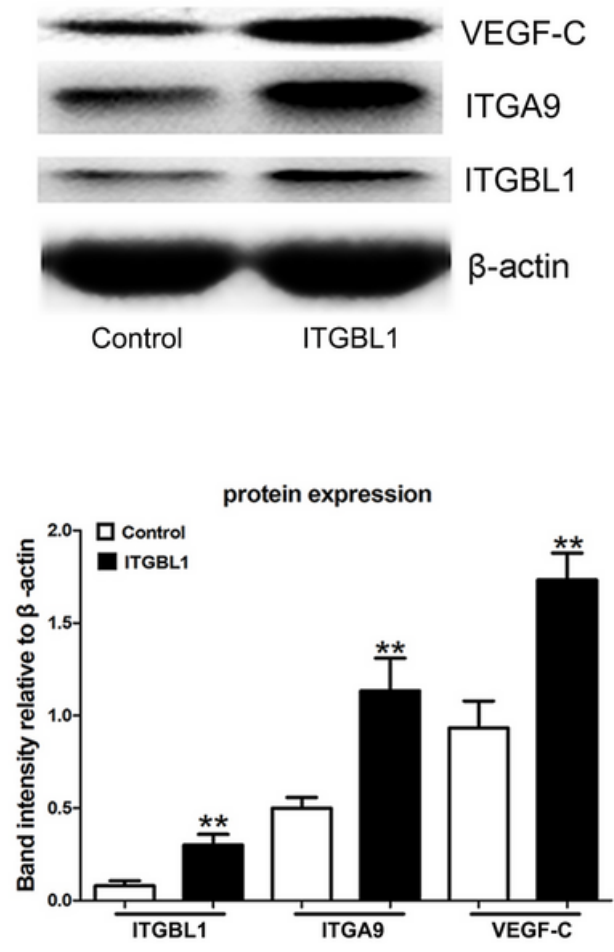

\section{Figure 6}

Correlation between ITGBL1 and ITGA9/VEGF-C signaling pathway. a the bioinformatics analysis showed the strong correlation between ITGBL1 expression and the ITGA9/VEGF-C signaling pathway.b The bioinformatics 
analysis that ITGBL1 was the positive relationship and co-expressed with VEGF-C in various tumors such as, colon cancer. c,d Increasing ITGBL1 expression could promote the expression of ITGA9, and ITGA9 could promote the expression of VEGF-C. e The concentration of VEGF-C in the supernatant of cells transfected with ITGBL1 was increased. *, $\mathrm{P}<0.05 ; * *, \mathrm{P}<0.01$.

a

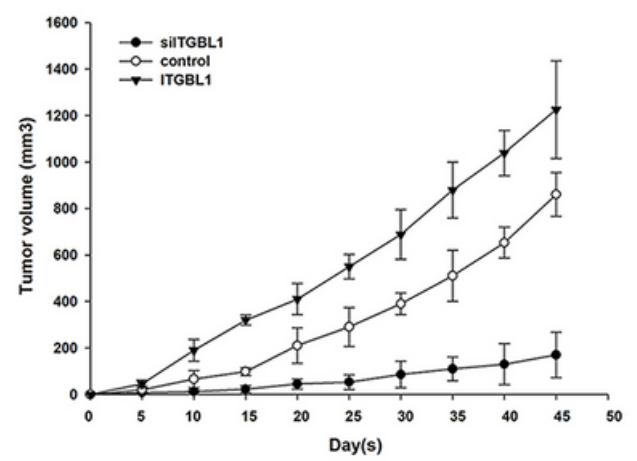

C

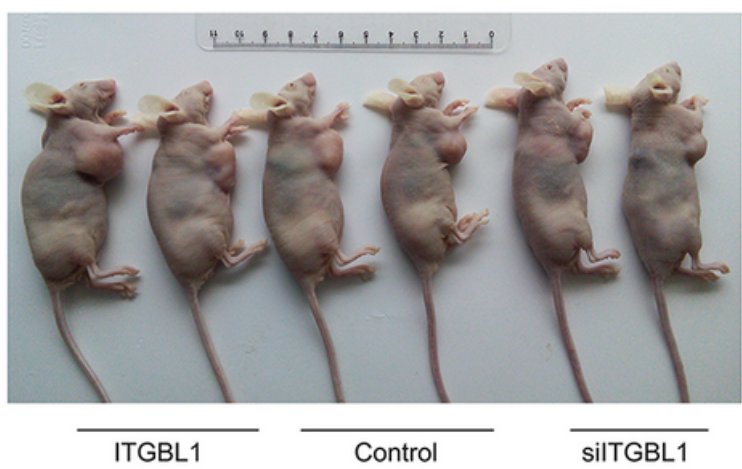

e

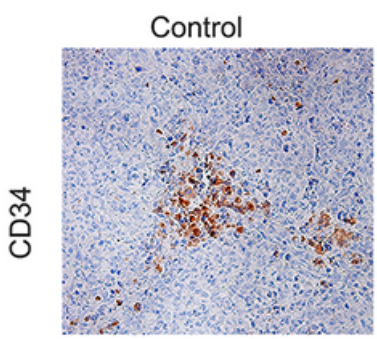

Control

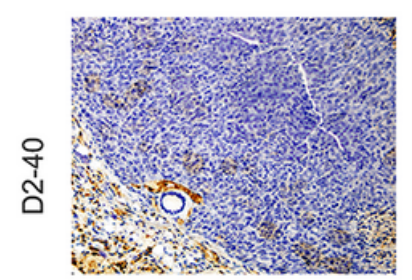

ITGBL1

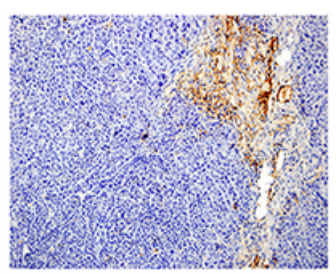

b

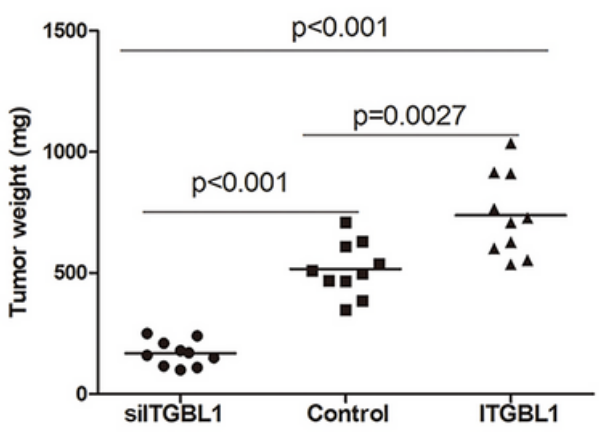

d

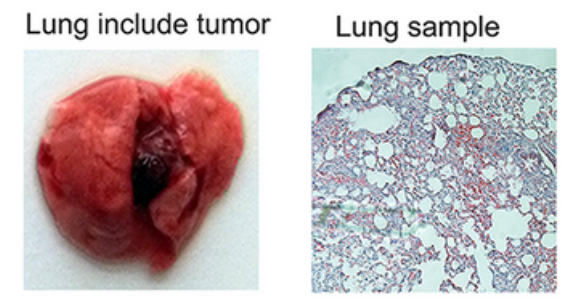

Metastases to the lungs
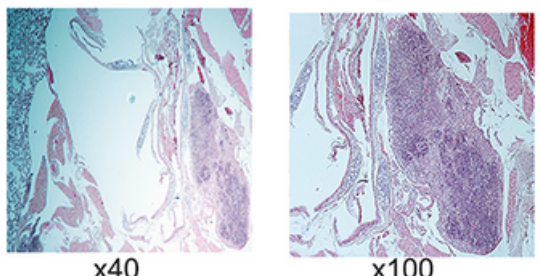

silTGBL1

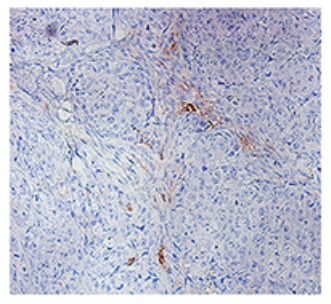

silTGBL1

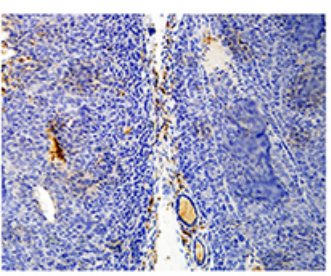

\section{Figure 7}

ITGBL1 promotes tumor growth, angiogenesis, lymphangiogenesis and metastasis in nude mice. a,b,c The tumor volume and weight were significantly greater in the ITGBL1 overexpression group than in the NC group. On the other hand, the tumor volume and weight were the lower in the ITGBL1 inhibitor group than in the NC 
group. $d$ These serial sections of the lungs stained with hematoxylin-eosin were used to identify metastatic lesions in the ITGBL1 group. e The density of tumor blood vessels and lymph vessel found in the tumor nodules of the ITGBL1 overexpression group was much higher than those in the NC group and the ITGBL1 inhibitor group.

\section{Supplementary Files}

This is a list of supplementary files associated with this preprint. Click to download.

- SupplementaryMaterial.docx 